\title{
Differences in the Performance of Allyl Based Palladium Precatalysts for Suzuki-Miyaura Reactions
}

\author{
Matthew R. Espinosa, ${ }^{\mathrm{a}}$ Angelino Doppiu, ${ }^{\mathrm{b}}$ and Nilay Hazari ${ }^{\mathrm{a}, *}$ \\ a Department of Chemistry, Yale University, P. O. Box 208107, New Haven, Connecticut, 06520, \\ USA. E-mail: nilay.hazari@yale.edu.

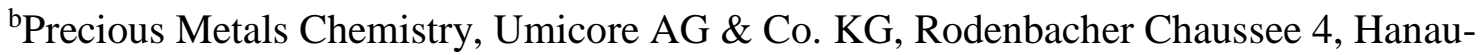 \\ Wolfgang, Germany.
}

\begin{abstract}
Palladium(II) precatalysts are used extensively to facilitate cross-coupling reactions because they are bench stable and give high activity. As a result, precatalysts such as Buchwald's palladacycles, Organ's PEPPSI species, Nolan's allyl-based complexes, and Yale's 1-tert-butylindenyl containing complexes, are all commercially available. Comparing the performance of the different classes of precatalysts is challenging because they are typically used under different conditions, in part because they are reduced to the active species via different pathways. However, within a particular class of precatalyst, it is easier to compare performance because they activate via similar pathways and are used under the same conditions. Here, we evaluate the activity of different allylbased precatalysts, such as $\left(\eta^{3}\right.$-allyl $) \operatorname{PdCl}(L),\left(\eta^{3}-\operatorname{crotyl}\right) \operatorname{PdCl}(\mathrm{L}),\left(\eta^{3}-\operatorname{cinnamyl}\right) \operatorname{PdCl}(\mathrm{L})$, and $\left(\eta^{3}-\right.$ 1-tert-butylindenyl)PdCl(L) in Suzuki-Miyaura reactions. Specifically, we evaluate precatalyst performance as the ancillary ligand (NHC or phosphine), reaction conditions, and substrates are varied. In some cases, we connect relative activity to both the mechanism of activation and the prevalence of the formation of inactive palladium(I) dimers. Additionally, we compare the performance of in situ generated precatalysts with commonly used palladium sources such as tris(dibenzylideneacetone)dipalladium(0) $\quad\left(\mathrm{Pd}_{2} \mathrm{dba}_{3}\right), \quad$ bis(acetonitrile)dichloropalladium(II) $\left(\mathrm{Pd}\left(\mathrm{CH}_{3} \mathrm{CN}\right)_{2} \mathrm{Cl}_{2}\right)$, and palladium acetate. Our results provide information about which precatalyst to use under different conditions.
\end{abstract}




\section{Introduction}

Palladium-catalyzed cross-coupling reactions are widely used in both industry and academia due to their reliability and versatility. ${ }^{[1]}$ One of the major reasons that cross-coupling

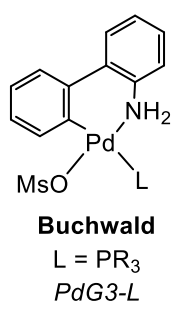
reactions are so effective is that there are a variety of specialized phosphine and $\mathrm{N}$-heterocyclic carbene (NHC)
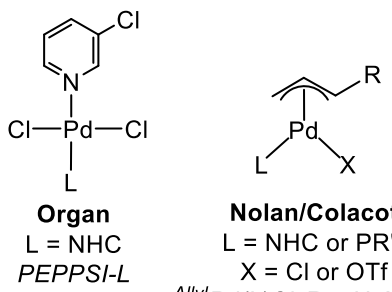

Nolan/Colacot

$\mathrm{L}=\mathrm{NHC}$ or $\mathrm{PR}_{3}$ $\mathrm{X}=\mathrm{Cl}$ or OTf

Allyl $P d(L) C l ; \mathrm{R}=\mathrm{H} ; \mathrm{X}=\mathrm{Cl}$ Crotyl $P d(L) C l ;_{\mathrm{R}}=\mathrm{Me} ; \mathrm{X}=\mathrm{Cl}$ Cinnamyl $P d(L) C l ; \mathrm{R}=\mathrm{Ph} ; \mathrm{X}=\mathrm{C}$

Figure 1: Selected examples of commercially available palladium(II) precatalysts for cross-coupling reactions.

ligands that can promote the elementary steps in catalysis. ${ }^{[2]}$ These ligands also stabilize monoligated palladium(0), which is proposed to be the active species in many cross-coupling reactions, but they often have comparable expense to the palladium source. ${ }^{[3]}$ Thus, the traditional route for forming the active species, the addition of excess ligand to a palladium(0) complex, is no longer attractive. Instead, several well-defined palladium(II) precatalysts with a 1:1 palladium to ligand ratio that are reduced in situ to palladium(0) have been developed and are now commercially available. ${ }^{[3]}$ Common examples of palladium(II) precatalysts include Buchwald palladacycles, ${ }^{[4]}$ Organ's PEPPSI precatalysts, ${ }^{[5]}$ Nolan's allyl-based systems, ${ }^{[2 \mathrm{~d}, 6]}$ and the related 1-tertbutylindenyl-based precatalyst developed at Yale (Figure 1). ${ }^{[7]}$ Although it would be valuable for researchers to understand the relative performance of the different types of precatalysts, comparing catalytic activity across different precatalyst classes is challenging because they are typically used under different reaction conditions and have different pathways for activation. In contrast, comparing the activity of precatalysts within a particular class should be more straightforward, as in this case, they are normally used under the same conditions.

Allyl-based precatalysts, which were developed by Nolan, can feature either an unsubstituted $\eta^{3}$ allyl, $\eta^{3}$-crotyl, or $\eta^{3}$-cinnamyl ligand and are used to facilitate a plethora of cross-coupling reactions. ${ }^{[2 \mathrm{~d}]}$ Although these systems were initially developed for use with NHC ligands, the Colacot and Shaughnessy groups established that phosphine ligands are also compatible with allyltype systems. ${ }^{[6 e, 8]}$ However, when supported by certain phosphine or NHC ligands, allyl-type precatalysts can form palladium(I) dimers during activation, via a comproportionation reaction between the unreacted palladium(II) precatalyst and the monoligated palladium(0) active species (Figure 2). ${ }^{[6 e, 8-9]}$ The formation of palladium(I) dimers sequesters the active catalyst in a less 
reactive form and is proposed to lower catalytic activity. To prevent dimer formation, the bulkier Yale precatalyst, which features a $\eta^{3}$-1-tert-butylindenyl

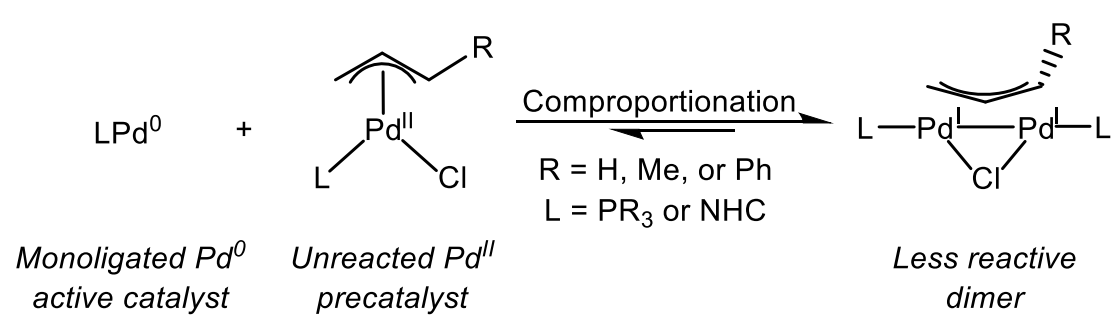
Figure 2: Comproportionation of palladium( 0 ) active catalyst and palladium(II) precatalyst to form inactive palladium(I) dimers.

ligand, was developed and

showed improved activity, although it was only directly compared to allyl-based precatalysts in a limited number of cross-coupling reactions. ${ }^{[7,9]}$

Apart from the prevalence of palladium(I) dimer formation during catalysis, the other key factor in the performance of allyl-based precatalysts is proposed to be their rate of activation from palladium(II) to palladium(0). ${ }^{[7,9]}$ To date, three main pathways have been proposed for activation of allyl-type precatalysts ${ }^{[10]}$ (Figure 3): (A) process in which a solvent alcohol with a $\beta$-hydrogen coordinates to the metal, is deprotonated by base, and then transfers a hydrogen to the allyl-type ligand ${ }^{[11]}$; (B) a process in which a nucleophile such as $\mathrm{OH}^{-}$or $\mathrm{O}^{t} \mathrm{Bu}^{-}$directly attacks the allyl-type $\operatorname{ligand}^{[6 \mathrm{~b}, 12]}$; or $(\mathrm{C})$ a process which involves transmetallation of the halide with a boronic acid followed by reductive elimination of the allyl-type ligand. ${ }^{[13]}$ Preliminary activation studies indicate that the Yale precatalyst activates faster than other allyl-based systems when the reaction proceeds through a solvent assisted pathway, but information on the relative rates of activation of the different allyl-based systems is limited. ${ }^{[10]}$ In fact, more generally, there is a lack of knowledge

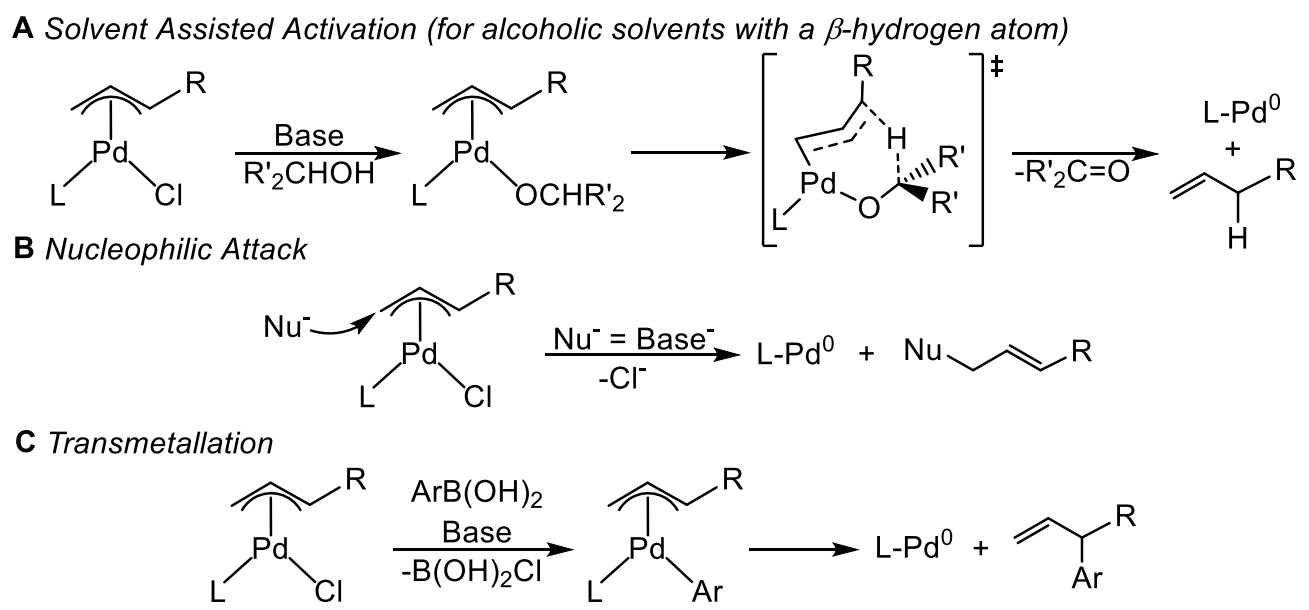

Figure 3: The three main pathways of precatalyst activation proposed for allyl-type precatalysts: (A) solvent assisted activation, (B) nucleophilic attack, and (C) transmetallation. 
about the relative catalytic activity of the different types of allyl-based precatalysts, especially when supported by different ancillary ligands.

Here, we examine the catalytic performance of a number of different allyl-type precatalysts for Suzuki-Miyaura reactions as the ancillary ligand (NHC or phosphine), reaction conditions, and substrates are varied. We use the results of these studies to make general comments about the types of reactions and conditions where there may be advantages to using a particular precatalyst and interpret our results in terms of the mechanism of activation. Additionally, we compare precatalysts to in situ systems generated from common palladium precursors, such as $\mathrm{Pd}(\mathrm{OAc})_{2}$ or $\mathrm{Pd}_{2} \mathrm{dba}_{3}$, and free ligand. Our results may assist researchers in selecting a precatalyst when they are performing Suzuki-Miyaura reactions.

\section{Results and Discussion}

To understand the activity of the different types of $\eta^{3}$-allyl-based precatalysts, we selected systems with a chloride ancillary ligand as these are commercially available for the $\eta^{3}$-allyl, $\eta^{3}$-crotyl, $\eta^{3}$ cinnamyl, and $\eta^{3}$-1-tert-butylindenyl scaffolds (Figure 1). We note that Colacot et al. have reported $\eta^{3}$-allyl-type precatalysts with a triflate ligand instead of a chloride ligand, but these systems are not as widely available and have not been synthesized for all of the different allyl systems. ${ }^{[6]}$ Precatalysts supported by both monodentate phosphine and NHC ligands were evaluated as these ligands are the most commonly used in cross-coupling reactions and comparing results with ligands of both types would enable us to understand the generality of our conclusions. ${ }^{[3]}$ The Suzuki-Miyaura reaction was used as the model reaction as it is by far the most prevalent cross-coupling reaction in synthetic chemistry. ${ }^{[14],[15]}$ Reactions were performed using a range of substrates, including heteroaryl chlorides, sterically bulky aryl chlorides, and nontraditional electrophiles, such as aryl esters, all of which require slightly different conditions. In most cases, our method for comparing precatalysts was to obtain kinetic data showing the yield of product versus time under conditions that had been previously reported in the literature. Kinetic data provides a higher quality assessment of relative performance than only comparing yield at a single time. Nevertheless, in some select cases, we compared precatalysts by measuring performance at a single time as it is operationally simpler. 
Coupling Reactions with Well-Defined Allyl-Type Precatalysts

$\underline{\text { NHC supported systems }}$

Mondentate NHC ligands are widely used as ancillary ligands in Suzuki-Miyaura reactions. ${ }^{[2 \mathrm{~d}, 6 \mathrm{c}, 6 \mathrm{~d}, 16]}$ This section explores the performance of NHC ligated allyl-type precatalysts for a variety of different reactions.

Simple aryl substrates: Our starting point was to perform a Suzuki-Miyaura coupling between 4chlorotoluene and phenyl boronic acid with precatalysts ligated with IPr, one of the most common NHC ligands used in cross-coupling. The reaction was performed under two sets of conditions; one was compatible with the weak base $\mathrm{K}_{2} \mathrm{CO}_{3}$ (Figure $4 \mathrm{~A}$ ) and the other with the strong base $\mathrm{KO}^{\mathrm{t}} \mathrm{Bu}$ (Figure 4B). ${ }^{[7]}$ In a similar fashion to what we have observed previously, ${ }^{[7]}$ the same trend is observed under both sets of conditions. Specifically, ${ }^{\text {BuInd }} \mathrm{Pd}(\mathrm{IPr}) \mathrm{Cl}$ displays the highest activity and is the only precatalyst that gives yields of greater than $80 \%$ after 6 hours. We propose that the lower yields found with ${ }^{\text {Cinnamyl }} \mathrm{Pd}(\mathrm{IPr}) \mathrm{Cl}$, ${ }^{\text {Crotyl }} \mathrm{Pd}(\mathrm{IPr}) \mathrm{Cl}$, and ${ }^{\text {Allyl }} \mathrm{Pd}(\mathrm{IPr}) \mathrm{Cl}$ are caused by their tendency to comproportionate and form off-cycle palladium(I) dimers with the IPr ligand (Figure

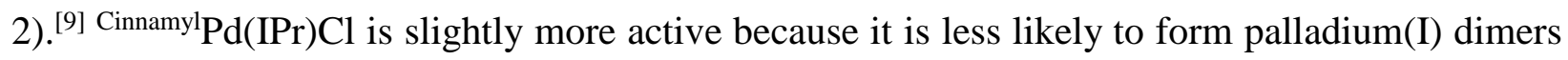
due to its increased steric bulk. ${ }^{[9]}$ In contrast, the steric bulk of ${ }^{\mathrm{tBu} I n d} \mathrm{Pd}(\mathrm{IPr}) \mathrm{Cl}$ means that it does not form palladium(I) dimers, which is why it has the highest activity. Further, under these conditions, activation to palladium(0) likely occurs via a solvent-mediated pathway (Figure 3), ${ }^{[10]}$ which is most efficient for the Yale precatalyst and is likely another reason for the observed higher activity. The same trends in precatalyst performance were observed when the catalyst loading was reduced from $0.5 \mathrm{~mol} \%$ to $0.1 \mathrm{~mol} \%$ (see $\mathrm{SI}$ ).

To assess if our results were relevant to other NHC ligands, we explored the catalytic activity of our library of precatalysts with the ligands IMes, IPr*OMe, and SIPr in the coupling of 4chlorotoluene and phenyl boronic acid under the optimized conditions for allyl-type precatalysts (see SI). Overall, IPr supported precatalysts are far more active than SIPr, IMes, or IPr*OMe ligated precatalysts, which is not unexpected as the nature of the ancillary ligand modifies the rates

of the elementary steps in catalysis and IPr is known to promote Suzuki-Miyaura reactions. ${ }^{[6 d]}$ However, the Yale precatalyst is typically the most active when all precatalysts are supported by the same ligand. The trends for the other precatalysts vary because some ancillary ligands require 
Condition A: 0.5 mol\% Precatalyst, 1.1 equiv. $\mathrm{K}_{2} \mathrm{CO}_{3}$

Condition B: $0.5 \mathrm{~mol} \%$ Precatalyst, 1.1 equiv. KO'Bu

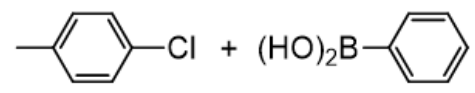

1.1 equiv.

$\mathrm{MeOH}:$ THF (19:1), RT, Time

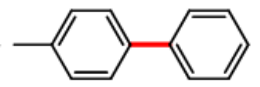

tBulnd $\mathrm{Pd}(\mathrm{IPr}) \mathrm{Cl}$

Cinnamy IPd(IPr)Cl

CrotylPd(IPr)Cl

Allyl Pd(IPr)Cl

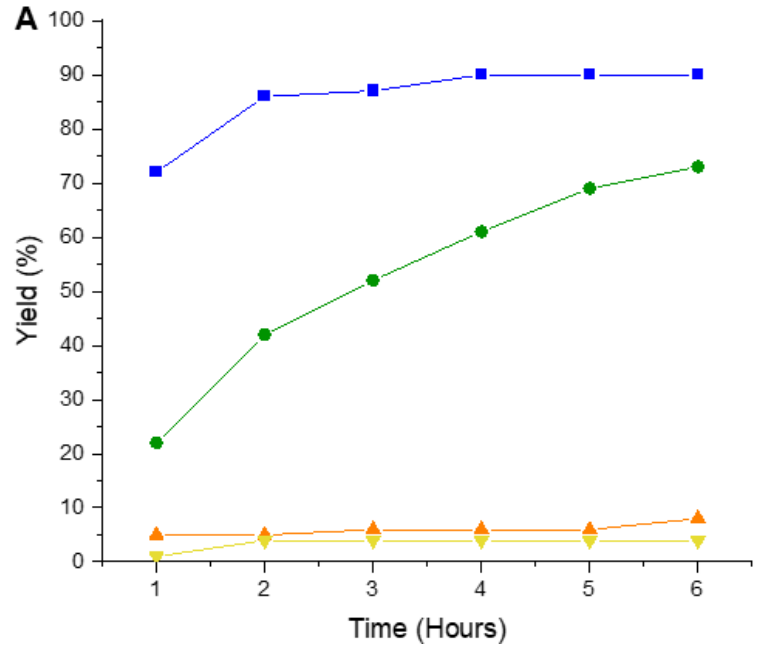

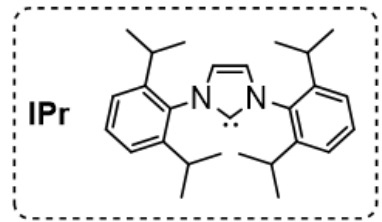

B 100

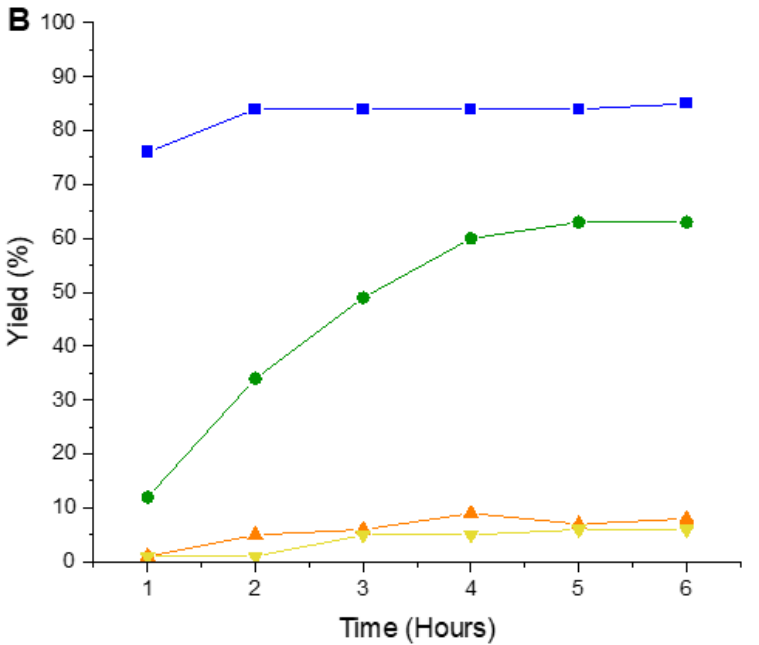

Figure 4: Yield versus time for the Suzuki-Miyaura coupling of 4-chlorotoluene and phenyl boronic acid using a weak base $\left(\mathrm{K}_{2} \mathrm{CO}_{3}\right)(\mathbf{A})$ or a strong base $(\mathrm{KO} B u)(\mathbf{B})$ with different precatalysts. Reaction conditions: $[\mathrm{ArCl}]=0.5 \mathrm{M}$, [Boronic Acid] $=0.55 \mathrm{M},[$ Base $]=0.55 \mathrm{M}$, [Precatalyst $]=0.0025 \mathrm{M}, 0.66$ $\mathrm{mL} \mathrm{MeOH}$, and $0.33 \mathrm{~mL}$ THF. Product yield was determined through comparison of product signal with an internal naphthalene standard on a gas chromatogram with an FID detector.

elevated temperatures to promote the catalytic reaction, and at these temperatures, palladium(I) dimer formation is reversible. ${ }^{[9,17]}$ In these cases, catalyst performance is presumably primarily related to the rate of initial solvent assisted activation, which with some NHC ligands follows the trend $\eta^{3}$-1-tert-butylindenyl $>\eta^{3}$-allyl $>\eta^{3}$-crotyl $\sim \eta^{3}$-cinnamyl ligand under these reaction conditions (vide supra). ${ }^{[10]}$ Nevertheless, at this stage activation rates have not been investigated with a large enough range of NHC ligands to explain all of our catalytic results.

Heteroaryl substrates: Active pharmaceutical ingredients often contain heteroaromatic groups, but heteroaryl substrates can be challenging to couple due to heteroatom coordination and/or protodeborylation. ${ }^{[2 \mathrm{f}, 18]}$ We evaluated the performance of different IPr-supported precatalysts in the Suzuki-Miyaura coupling of 2-chloro-4,6-dimethoxypyrimidine and benzo[b]furan-2-boronic acid under the optimized conditions for allyl precatalysts in the literature (Figure 5A). Under these 
A

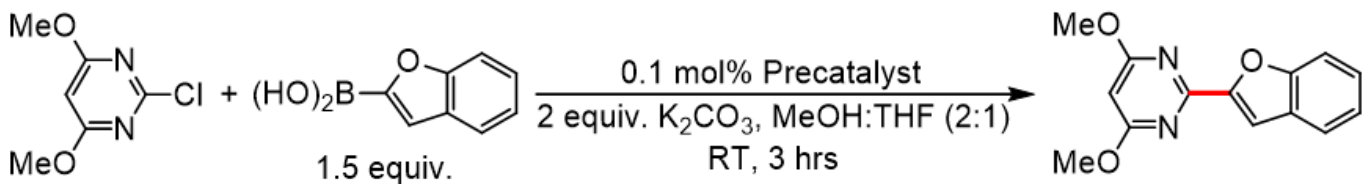

B
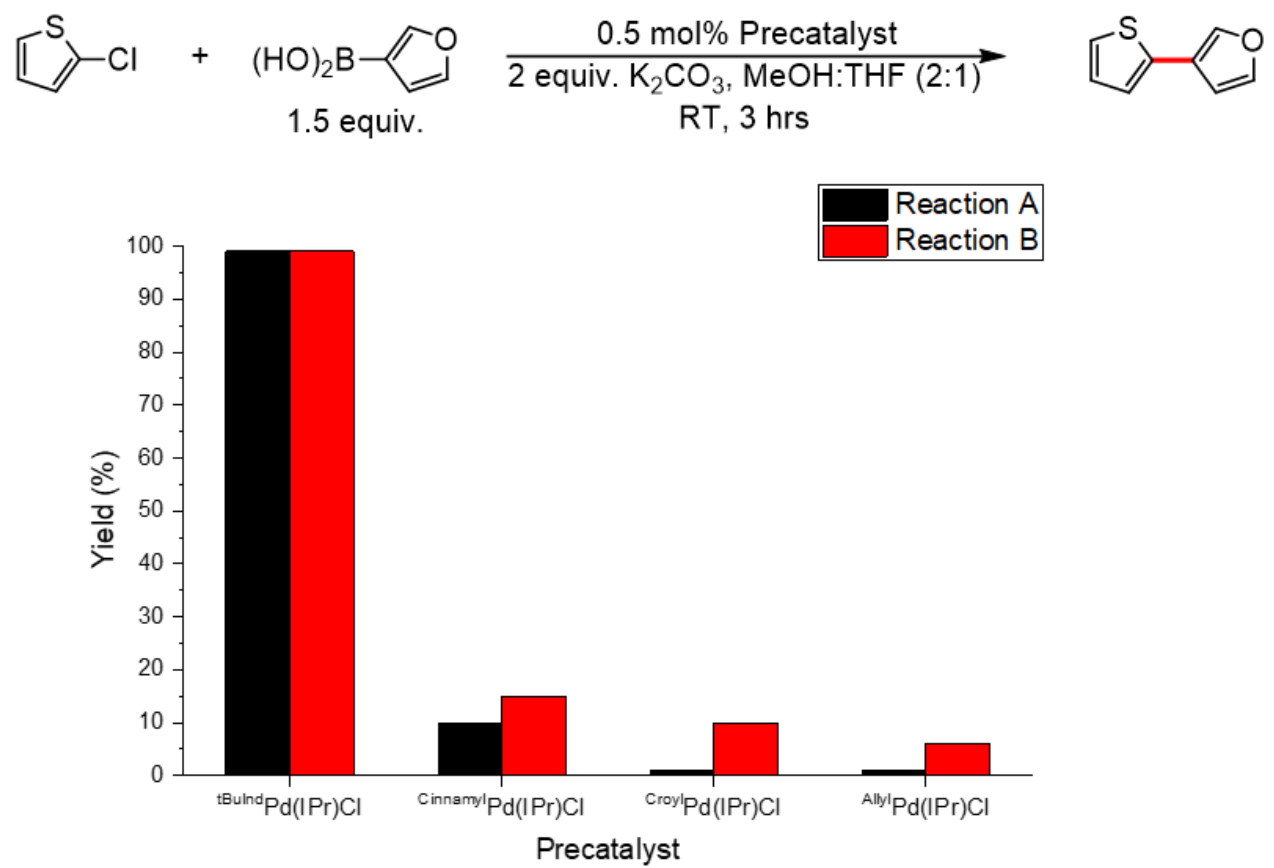

Figure 5: Comparative yields for Suzuki-Miyaura couplings of (A) 2-chloro-4,6-dimethoxypyrimidine and benzo[b]furan-2-boronic acid and (B) 2-chloro-4,6-dimethoxypyrimidine and 3-furan boronic acid. Reaction conditions A: $[\mathrm{ArCl}]=0.3 \mathrm{M}$, [Boronic Acid] $=0.45 \mathrm{M},[$ Base $]=0.6 \mathrm{M},[$ Precatalyst $]=0.0003$ $\mathrm{M}, 0.66 \mathrm{~mL} \mathrm{MeOH}$, and $0.33 \mathrm{~mL}$ THF. Reaction conditions $\mathrm{B}:[\mathrm{ArCl}]=0.3 \mathrm{M}$, [Boronic Acid] $=0.45$ $\mathrm{M}$, $[$ Base $]=0.6 \mathrm{M}$, [Precatalyst $]=0.0015 \mathrm{M}, 0.66 \mathrm{~mL} \mathrm{MeOH}$, and $0.33 \mathrm{~mL}$ THF. Product yield was determined through comparison of product signal with an internal naphthalene standard on a gas chromatogram with an FID detector.

conditions, ${ }^{\text {tBuInd }} \mathrm{Pd}(\mathrm{IPr}) \mathrm{Cl}$ achieved full conversion in 3 hours, whereas the other precatalysts displayed significantly lower activity at this time. Consistent with our results in Figure 4, ${ }^{\text {Cinnamyl }} \mathrm{Pd}(\mathrm{IPr}) \mathrm{Cl}$ displayed higher activity than either ${ }^{\mathrm{Allyl}} \mathrm{Pd}(\mathrm{IPr}) \mathrm{Cl}$ or ${ }^{\mathrm{Crotyl}} \mathrm{Pd}(\mathrm{IPr}) \mathrm{Cl}$, which is again likely due to the reduced formation of palladium(I) dimers with the more sterically bulky system. Further, in coupling reactions with heteroaryl substrates, the exact identity of the heteroatoms can have a significant impact on the reaction because it alters the ability of a substrate to coordinate to the metal center. Therefore, we performed a coupling reaction with different heteroaryl substrates. Namely, we coupled 2-chlorothiophene and 3-furan boronic acid and observed the same trends as for the coupling of 2-chloro-4,6-dimethoxypyrimidine and benzo[b]furan-2-boronic acid (Figure 5B). 
Sterically demanding substrates: Tetra-ortho substituted biaryls have historically been difficult to form through cross-coupling reactions. ${ }^{[\mathrm{d}]}$ As the sterically bulky IPr*OMe ligand is known to facilitate the formation of these products, we chose to compare IPr*OMe ligated precatalysts for the coupling of 2,6-dimethyl-1-chlorobenzene with 2,4,6-trimethylphenyl boronic acid (Figure 6). ${ }^{[19]}$ For this transformation, all of the systems examined give comparable activity, with the exception of the unsubstituted $\eta^{3}$-allyl precatalyst, which is slightly slower. The most likely explanation for the relatively similar activity of all of the precatalysts is that the steric bulk of the IPr*OMe ligand inhibits the formation of palladium(I) dimers. ${ }^{[6]}$ As a result, precatalyst performance is based mainly on the rate of activation of the precatalyst from palladium(II) to palladium(0). In this reaction, precatalyst activation likely involves nucleophilic attack by $\mathrm{OH}^{-}$on the allyl-type ligand, as there is no alcoholic solvent with a $\beta$-hydride and transmetallation is likely slow due to the steric bulk of the substrates. Based on the relatively similar rates of product formation for all precatalysts, it appears that activation via this pathway occurs at similar rates for

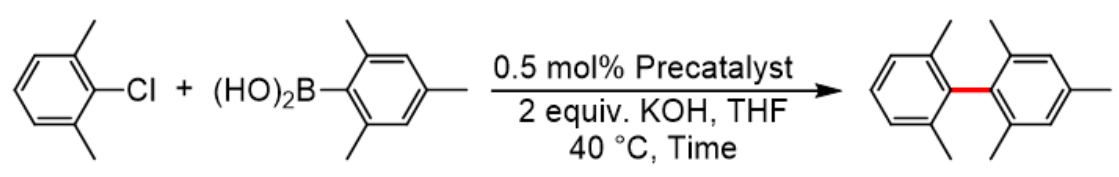

1.5 equiv.

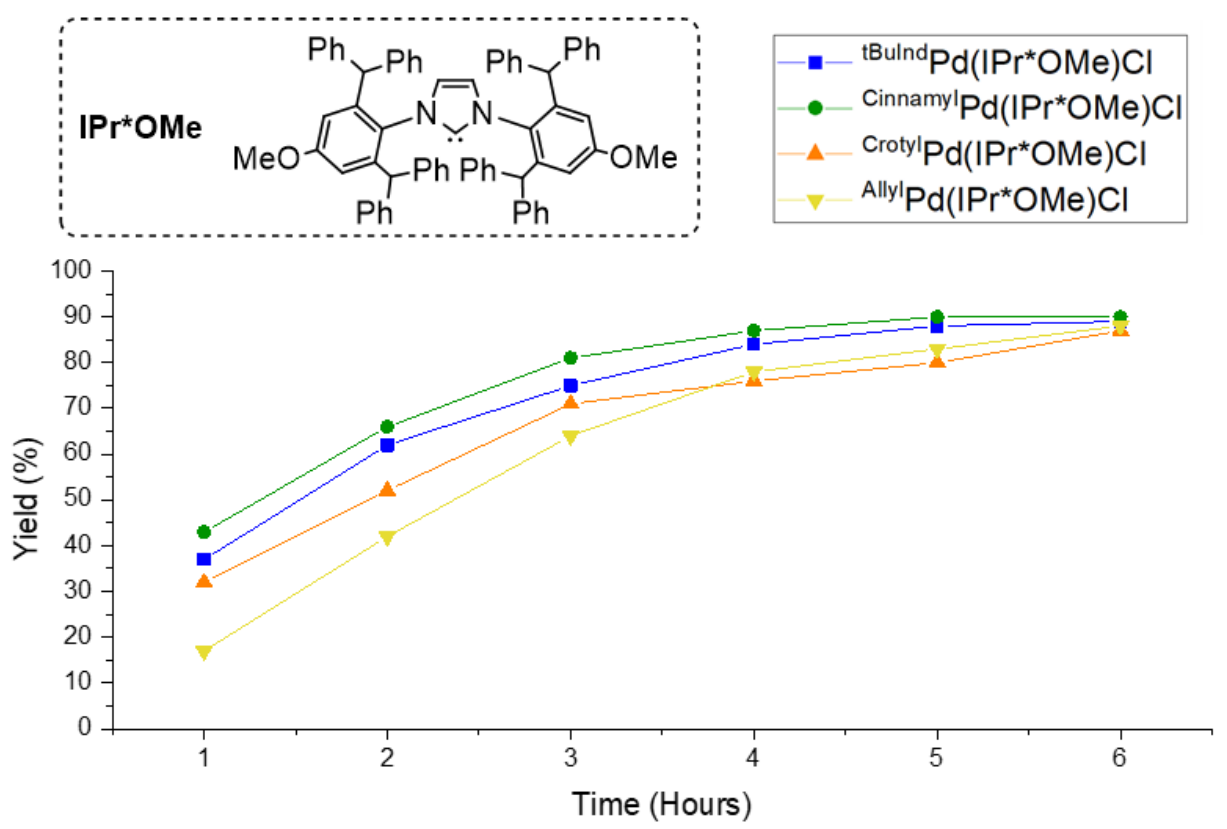

Figure 6: Yield versus time for the Suzuki-Miyaura coupling of 2,6-dimethyl-1-chlorobenzene and 2,4,6-trimethylphenyl boronic acid with different precatalysts. Reaction conditions: $[\mathrm{ArCl}]=0.25 \mathrm{M}$, $[$ Boronic Acid $]=0.375 \mathrm{M}$, [Base $]=0.5 \mathrm{M}$, [Precatalyst $]=0.00125 \mathrm{M}$, and $1 \mathrm{~mL}$ THF. Product yield was determined through comparison of product signal with an internal naphthalene standard on a gas chromatogram with an FID detector. 
all systems. This stands in contrast to activation via a solvent assisted pathway, where the Yale precatalyst is proposed to activate more rapidly than other allyl based systems. ${ }^{[10]}$

Non-traditional electrophiles: The vast majority of Suzuki-Miyaura reactions use aryl halides (or pseudo halides) as the electrophile, but in recent times cross-coupling reactions have been extended to include a variety of non-traditional electrophiles. ${ }^{[\mathrm{h}]}$ For example, it has been demonstrated that palladium precatalysts can couple phenyl esters through cleavage of the $\mathrm{C}_{\text {acyl- }} \mathrm{O}$ bond to generate ketones as products. ${ }^{[20]}$ We evaluated IPr-ligated precatalysts in a SuzukiMiyaura reaction between phenyl benzoate and 4-methoxy phenyl boronic acid (Figure 7). ${ }^{t B u I n d} \mathrm{Pd}(\mathrm{IPr}) \mathrm{Cl}$ shows the highest activity with the rate of product formation being slightly slower for ${ }^{\text {Cinnamyl }} \mathrm{Pd}(\mathrm{IPr}) \mathrm{Cl}$. Almost no conversion was observed with ${ }^{\text {Allyl }} \mathrm{Pd}(\mathrm{IPr}) \mathrm{Cl}$ or ${ }^{\text {Crotyl }} \mathrm{Pd}(\mathrm{IPr}) \mathrm{Cl}$. The improved performance of ${ }^{\text {Cinnamyl }} \mathrm{Pd}(\mathrm{IPr}) \mathrm{Cl}$ relative to ${ }^{\text {tBuInd }} \mathrm{Pd}(\mathrm{IPr}) \mathrm{Cl}$ in this reaction with the $\mathrm{IPr}$ ligand is likely because activation of the precatalyst from palladium(II) to palladium(0), which likely occurs via nucleophilic attack, is faster under these conditions which reduces the amount of off-cycle palladium(I) dimer formation.

Summary: Our data on the performance of allyl-type precatalysts with NHC ligands is consistent with performance being related to palladium(I) dimer formation and the rate of activation from

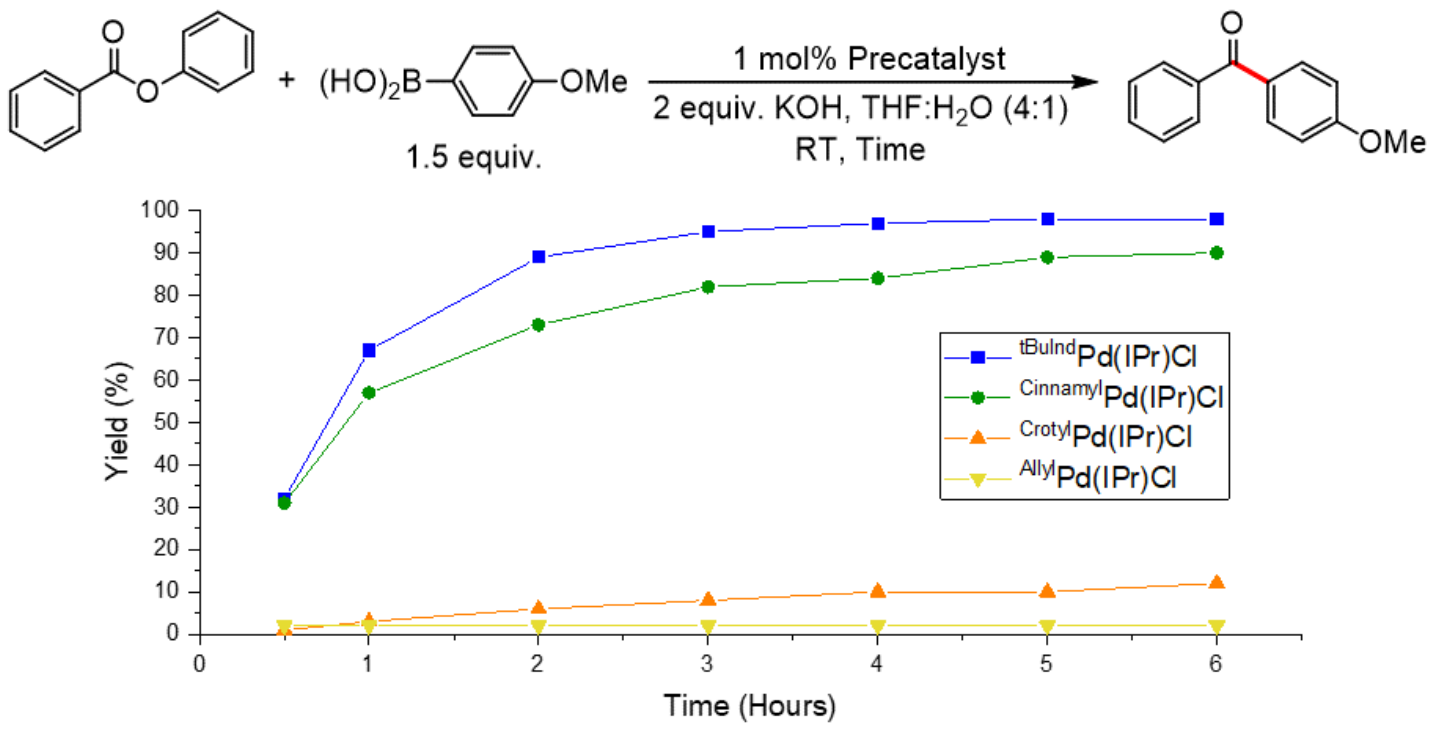

Figure 7: Yield versus time for the Suzuki-Miyaura coupling of phenyl benzoate and 4-methoxy phenyl boronic acid with different precatalysts. Reaction conditions: [Phenyl Benzoate] $=0.2 \mathrm{M}$, [Boronic Acid $]=0.3 \mathrm{M}$, [Base] $=0.4 \mathrm{M}$, [Precatalyst $]=0.002 \mathrm{M}, 0.2 \mathrm{~mL} \mathrm{H}_{2} \mathrm{O}$, and $0.8 \mathrm{~mL}$ THF. Product yield was determined through comparison of product signal with an internal naphthalene standard on a gas chromatogram with an FID detector. 
palladium(II) to palladium(0) (Figure 8). For systems, where palladium(I) dimer formation can occur, typically with ancillary ligands with moderate steric bulk, such as IPr, ${ }^{\mathrm{tBuInd}} \mathrm{Pd}(\mathrm{NHC}) \mathrm{Cl}$ will likely give the highest activity, followed by ${ }^{\text {Cinnamyl }} \mathrm{Pd}(\mathrm{NHC}) \mathrm{Cl}$. In contrast, in systems where the ancillary ligand is sufficiently sterically bulky to prevent palladium(I) dimer formation, precatalyst performance is related to the rate of activation from palladium(II) to palladium(0). Our results suggest that when activation occurs via a solvent assisted pathway ${ }^{\mathrm{tBuInd}} \mathrm{Pd}(\mathrm{NHC}) \mathrm{Cl}$ will give the best performance. However, for systems where activation can occur via another mechanism, such as nucleophilic attack, the relative ordering of activity of the allyl-type precatalysts is not clear and in some cases all systems may give comparable activity.

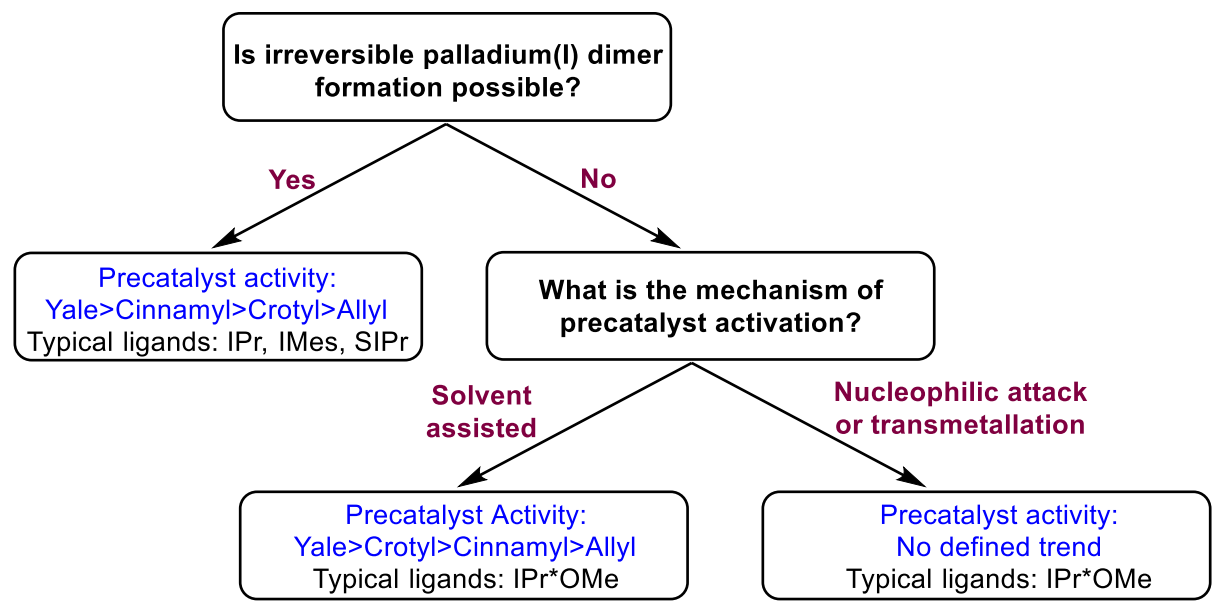

Figure 8: Decision tree for selecting NHC ligated precatalysts.

\section{Phosphine Ligands}

Phosphine ligands are more commonly used in Suzuki-Miyaura reactions than NHC ligands. ${ }^{[1 \mathrm{~h}, 2 \mathrm{f}, 2 \mathrm{~g}]}$ This section compares the performance of phosphine ligated allyl-type precatalysts for a variety of different reactions.

Simple aryl substrates: Initially, we performed a Suzuki-Miyaura coupling between 4chlorotoluene and phenyl boronic acid with precatalysts ligated with the XPhos ligand (one of the most common phosphine ligands used in cross-coupling) under both weak $\left(\mathrm{K}_{2} \mathrm{CO}_{3}\right)$ and strong $\left(\mathrm{KO}{ }^{t} \mathrm{Bu}\right.$ ) base conditions (Figure 9). Similar to results found with NHC ligands, ${ }^{\text {tBuInd }} \mathrm{Pd}(\mathrm{XPhos}) \mathrm{Cl}$ gives the highest activity, which is likely due to its more rapid activation in methanol, via a solvent assisted pathway (Figure 3) ${ }^{[10]}$ In this case, palladium(I) dimer formation is unlikely to be a significant factor in catalysis as previous results from Colacot, suggest that XPhos is too sterically 
bulky to allow dimer formation. ${ }^{[6 e]}$ Consistent with this proposal, the less sterically bulky ${ }^{\text {Crotyl }} \mathrm{Pd}(\mathrm{XPhos}) \mathrm{Cl}$ outperforms ${ }^{\text {Cinnamyl }} \mathrm{Pd}(\mathrm{XPhos}) \mathrm{Cl}$. In an analogous fashion to the IPr supported systems, the same trends in precatalyst activity are observed when the catalyst loading is reduced to $0.1 \mathrm{~mol} \%$ (see SI). Given that the rate of activation from palladium(II) to palladium(0) is

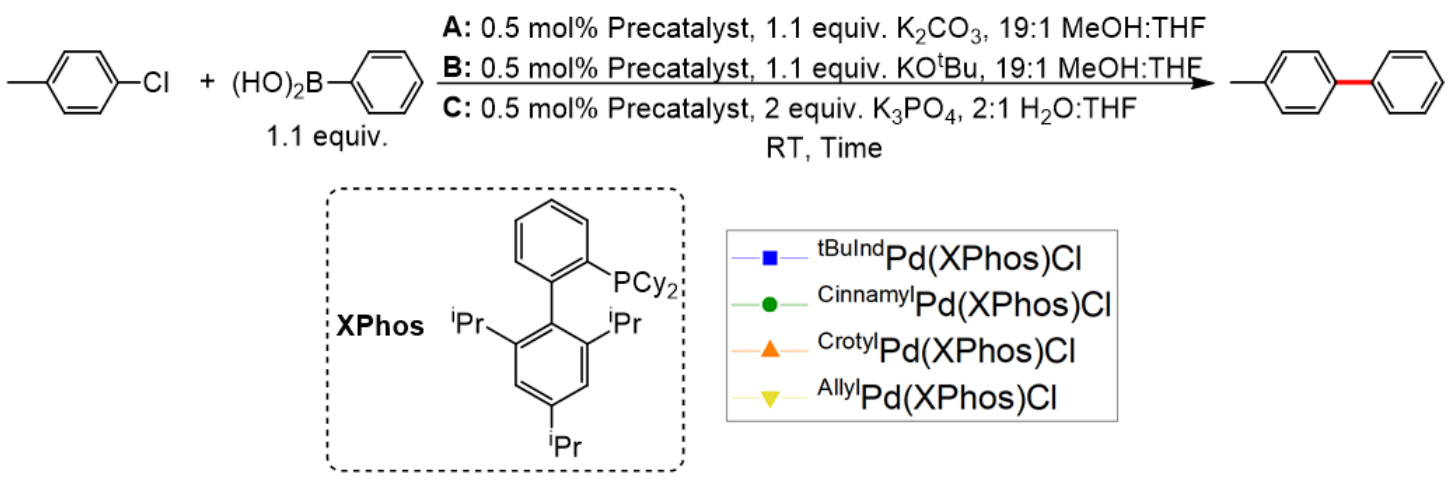

A

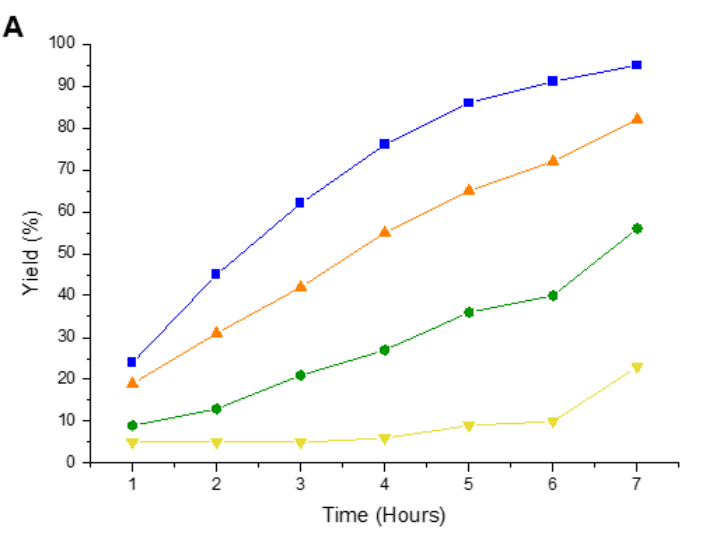

B

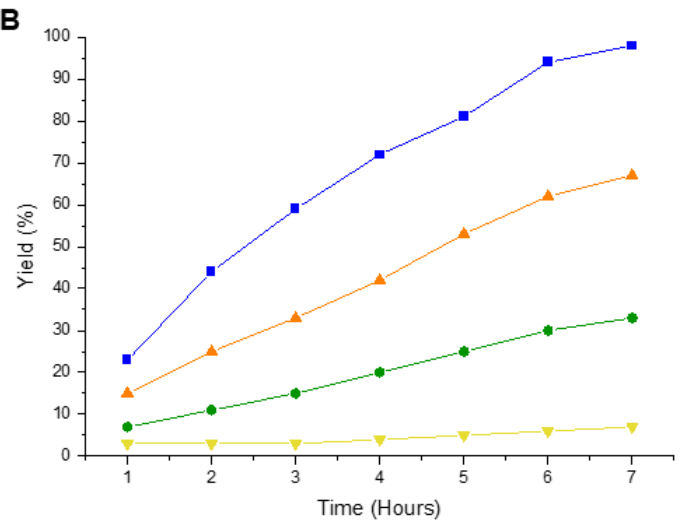

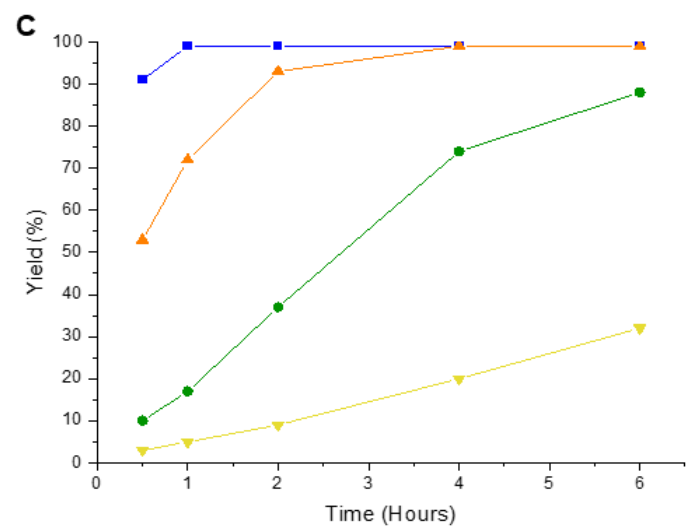

Figure 9: Yield versus time for the Suzuki-Miyaura coupling of 4-chlorotoluene and phenyl boronic acid with $\mathrm{K}_{2} \mathrm{CO}_{3}(\mathbf{A}), \mathrm{KO}^{t} \mathrm{Bu}(\mathbf{B})$, and $\mathrm{K}_{3} \mathrm{PO}_{4}(\mathbf{C})$ using XPhos ligated precatalysts. Reaction conditions $(\mathbf{A}$ and $\mathbf{B}):[\mathrm{ArCl}]=0.5 \mathrm{M}$, [Boronic Acid $]=0.55 \mathrm{M},[$ Base $]=0.55 \mathrm{M}$, [Precatalyst $]=0.0025 \mathrm{M}, 0.95$ $\mathrm{mL} \mathrm{MeOH}$, and $0.05 \mathrm{~mL}$ THF. Reaction conditions $(\mathbf{C}):[\mathrm{ArCl}]=0.5 \mathrm{M}$, [Boronic Acid] $=0.55 \mathrm{M}$, $[$ Base $]=1.0 \mathrm{M}$, [Precatalyst $]=0.0025 \mathrm{M}, 0.66 \mathrm{~mL} \mathrm{MeOH}$, and $0.33 \mathrm{~mL}$ THF. Product yield was determined through comparison of product signal with an internal naphthalene standard on a gas chromatogram with an FID detector. 
proposed to be the determining factor in precatalyst activity with sterically bulky phosphines, we explored the relative activity of allyl precatalysts, supported by the bulky ligand XPhos, under different conditions. To this end, we coupled 4-chlorotoluene and phenyl boronic acid using THF and water with a weak base, $\mathrm{K}_{3} \mathrm{PO}_{4}$, in order to prevent activation via a solvent assisted pathway (Figure 9C). Despite the change in the activation pathway, presumably to nucleophilic attack, the relative precatalyst activity did not change, suggesting that the rates of activation via a pathway involving nucleophilic attack are the same as those involving a solvent assisted pathway.

We also evaluated the relative performance of precatalysts supported by SPhos, RuPhos, and $\mathrm{P}^{\mathrm{t}} \mathrm{Bu}_{3}$ (see SI). As the ancillary ligand was changed, ${ }^{\mathrm{tBuInd}} \mathrm{Pd}(\mathrm{L}) \mathrm{Cl}$ remained the most active precatalyst, which is consistent with results found using XPhos. However, the relative activities of the other allyl precatalysts varied as the ancillary ligand was changed. No clear trends could be discerned from our data, but it did appear that in systems with smaller ancillary ligands, cinnamyl supported systems are more active than crotyl or allyl supported systems, presumably because palladium(I) dimer formation is important in these cases. In contrast, for sterically bulky systems, the rate of activation from palladium(II) to palladium(0), which is not completely understood, is presumably the predominant factor.

Heteroaryl substrates: We next evaluated XPhos ligated precatalysts in Suzuki-Miyaura couplings involving heteroaryl substrates. Initially, we performed a reaction between 2-chloro-4,6dimethoxypyrimidine and benzo[b]furan-2-boronic acid (Figure 10). The performance of the precatalysts is different from that observed for simple substrates. Although ${ }^{\mathrm{tBuInd}} \mathrm{Pd}(\mathrm{XPhos}) \mathrm{Cl}$ is still the most active system, ${ }^{\text {Crotyl}} \mathrm{Pd}(\mathrm{XPhos}) \mathrm{Cl}$ is the least active. ${ }^{\text {Allyll }} \mathrm{Pd}(\mathrm{XPhos}) \mathrm{Cl}$ is the second most active and gives slightly superior activity to ${ }^{\text {Cinnamyl }} \mathrm{Pd}(\mathrm{XPhos}) \mathrm{Cl}$. This data suggests that the presence of heteroatoms makes a significant difference to the relative rates of precatalyst activation, which is presumably the sole determinant of activity, as palladium(I) dimer formation is not a significant issue with the XPhos ligand (vide supra). ${ }^{[6 \mathrm{e}]}$

To further evaluate the effect of heteroatoms, we performed a coupling reaction between 2chlorothiophene and 3-furan boronic acid (Figure 11). To our surprise, ${ }^{C r o t y l} \mathrm{Pd}(\mathrm{XPhos}) \mathrm{Cl}$ and ${ }^{\text {Cinnamyll }} \mathrm{Pd}(\mathrm{XPhos}) \mathrm{Cl}$ give the best activity, followed by ${ }^{\mathrm{Allyl}} \mathrm{Pd}(\mathrm{XPhos}) \mathrm{Cl}$ and ${ }^{\mathrm{tBuInd}} \mathrm{Pd}(\mathrm{XPhos}) \mathrm{Cl}$. We propose that the different trends in precatalyst performance are related to the ability of the substrate to participate in precatalyst activation with some allyl-type systems. Specifically, when 
3-furan boronic acid is used as a substrate, we hypothesize that the heteroatom assists activation via a pathway involving transmetallation and reductive elimination by facilitating pre-coordination

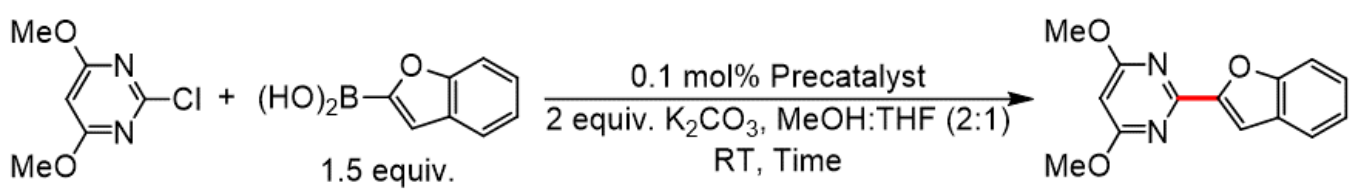

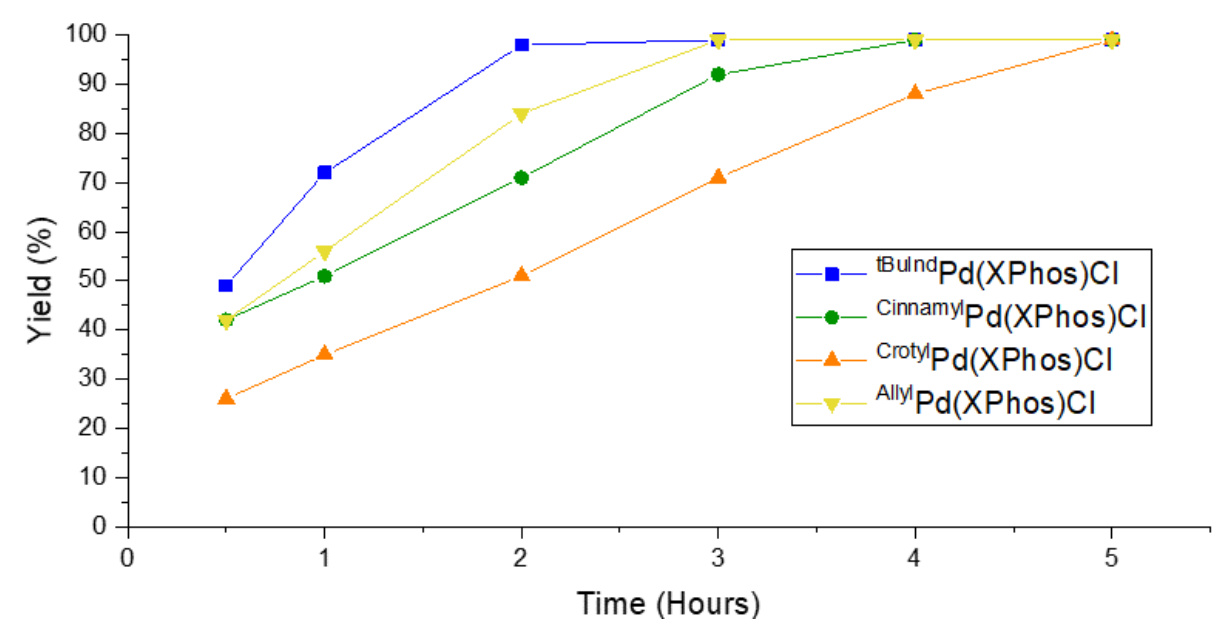

Figure 10: Yield versus time for the Suzuki-Miyaura coupling of 2-chloro-4,6-dimethoxypyrimidine and benzo[b]furan-2-boronic acid with different precatalysts. Reaction conditions: $[\mathrm{ArCl}]=0.3 \mathrm{M}$, $[$ Boronic Acid $]=0.45 \mathrm{M}$, [Base] $=0.6 \mathrm{M}$, [Precatalyst $]=0.0003 \mathrm{M}, 0.33 \mathrm{~mL} \mathrm{THF}$, and $0.67 \mathrm{~mL} \mathrm{MeOH}$. Product yield was determined through comparison of product signal with an internal naphthalene standard on a gas chromatogram with an FID detector.

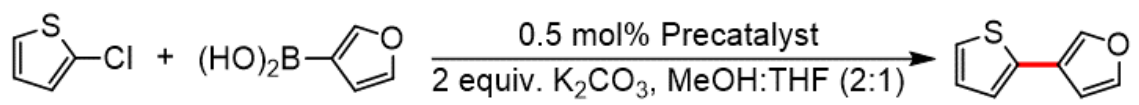

1.5 equiv.

RT, Time

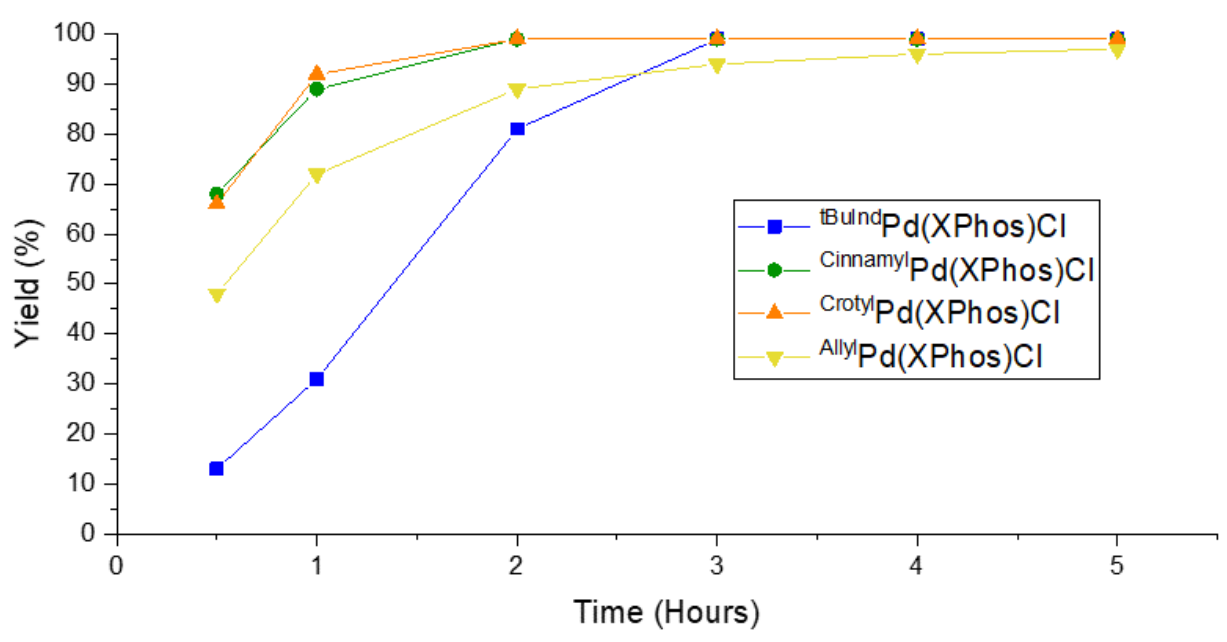

Figure 11: Yield versus time for the Suzuki-Miyaura coupling of 2-chlorothiophene and 3-furan boronic acid with different precatalysts. Reaction conditions: $[\mathrm{ArCl}]=0.3 \mathrm{M}$, [Boronic Acid] $=0.45 \mathrm{M}$, [Base] $=0.6 \mathrm{M}$, [Precatalyst] $=0.0015 \mathrm{M}, 0.33 \mathrm{~mL}$ THF, and $0.67 \mathrm{~mL} \mathrm{MeOH}$. Product yield was determined through comparison of product signal with an internal naphthalene standard on a gas chromatogram with an FID detector. 
of the substrate to the metal. In contrast, when the less nucleophilic benzo[b]furan-2-boronic acid is used, this pathway is less favorable. Further, we propose this effect is more notable for less sterically bulky precatalysts as coordination of the heteroatom is more facile. To more rigorously understand the effect of the boronic acid on relative precatalyst activity, we examined the coupling of 2-chloro-4,6-dimethoxypyrimidine and 2-furan boronic acid, which allows direct comparison to the reaction of 2-chloro-4,6-dimethoxypyrimidine and the less coordinating benzo[b]furan-2boronic acid (Figure 12). As expected, for ${ }^{\mathrm{tBuInd}} \mathrm{Pd}(\mathrm{XPhos}) \mathrm{Cl}$, there is relatively little difference in the yields after one hour, consistent with activation not involving the boronic acid, and oxidative addition being the turnover-limiting step in catalysis. In contrast, for ${ }^{\text {Crotyl }} \mathrm{Pd}(\mathrm{XPhos}) \mathrm{Cl}$ and ${ }^{\text {Cinnamyl }} \mathrm{Pd}(\mathrm{XPhos}) \mathrm{Cl}$, the yield of product is significantly higher after one hour in the reaction involving 2-furan boronic acid compared to the reaction with benzo[b]furan-2-boronic acid. In a result that we do not understand at this stage, ${ }^{\text {Allyl }} \mathrm{Pd}(\mathrm{XPhos}) \mathrm{Cl}$ did not give a significantly higher yield with 2-furan boronic acid compared to benzo[b]furan-2-boronic acid, although we note that it is often difficult to understand the performance of the unsubstituted system. Overall, ${ }^{\text {Crotyl }} \mathrm{Pd}(\mathrm{XPhos}) \mathrm{Cl}$ and ${ }^{\text {Cinnamyl }} \mathrm{Pd}(\mathrm{XPhos}) \mathrm{Cl}$ are the most active precatalysts for the coupling of 2furan boronic acid but ${ }^{\mathrm{tBuInd}} \mathrm{Pd}(\mathrm{XPhos}) \mathrm{Cl}$ is the most active precatalyst for the coupling of benzo[b]furan-2-boronic acid. This set of experiments introduces another variable in assessing the

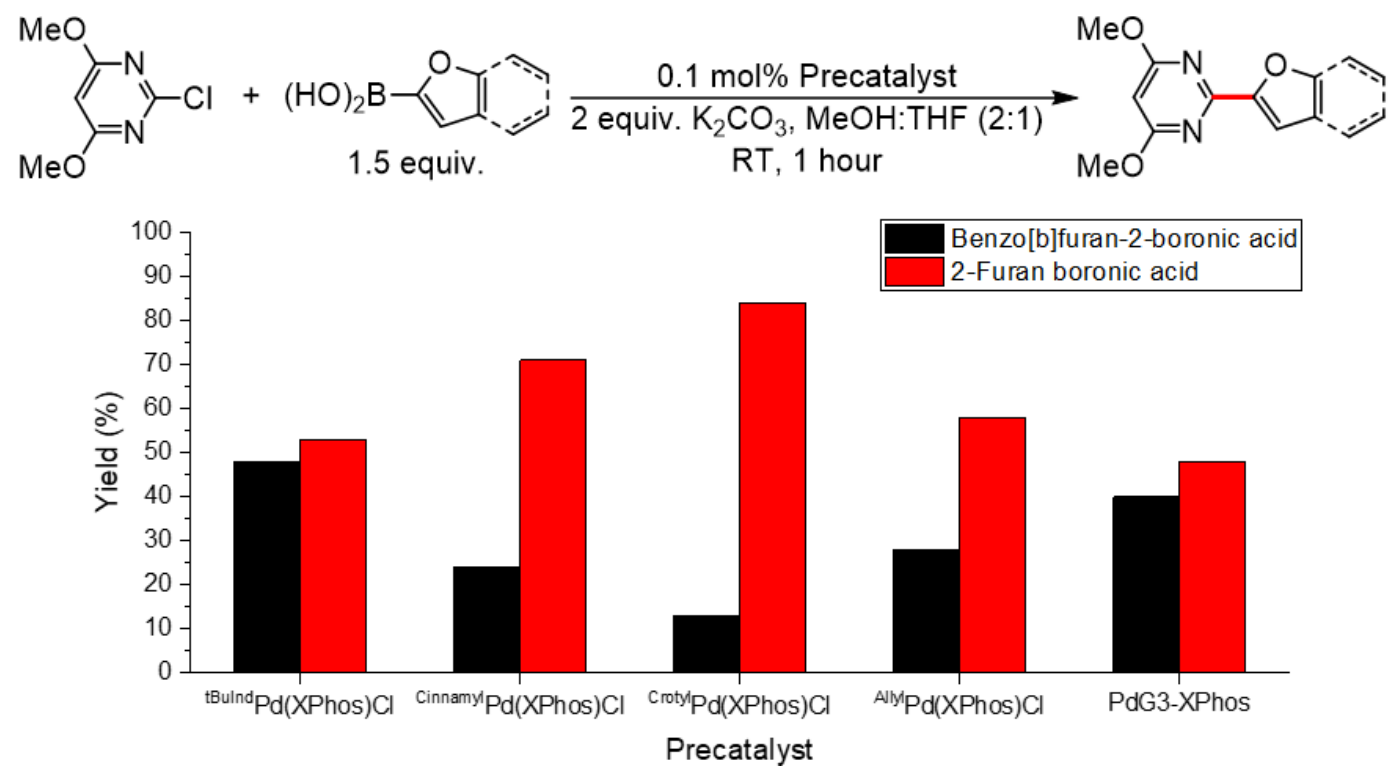

Figure 12: Comparative yields of the Suzuki-Miyaura coupling of 2-chloro-4,6-dimethoxypyrimidine with benzo[b]furan-2-boronic acid or 2-furan boronic acid with different precatalysts. Reaction conditions: $[\mathrm{ArCl}]=0.3 \mathrm{M}$, $[$ Boronic Acid $]=0.45 \mathrm{M},[$ Base $]=0.6 \mathrm{M},[$ Precatalyst $]=0.0003 \mathrm{M}, 0.33$ $\mathrm{mL} \mathrm{THF}$, and $0.67 \mathrm{~mL} \mathrm{MeOH}$. Product yield was determined through comparison of product signal with an internal naphthalene standard on a gas chromatogram with an FID detector. 
relative activity of precatalysts as it shows that performance is not only affected by reaction conditions but also by the exact nature of the substrates. The particular effect observed here, coordination of the boronic acid to promote activation via transmetallation, is likely limited to a relatively small number of substrates. Nevertheless, it provides an important reminder about the complexity of precatalyst comparison and suggests that when new substrates are utilized, there are likely benefits to evaluating different systems.

Non-traditional substrates: Aryl sulfamates are robust non-traditional electrophiles for crosscoupling that can be readily synthesized from ubiquitous phenols and are directing groups for $\mathrm{C}-$ $\mathrm{H}$ bond functionalization reactions. ${ }^{[21]}$ We examined our series of precatalysts in the coupling of 1-naphthyl sulfamate and 4-methoxyphenyl boronic acid using reaction conditions previously described in the literature (Figure 13). ${ }^{[22]}$ The only precatalyst that achieved yields above $90 \%$ after 6 hours was ${ }^{\text {tBuInd }} \mathrm{Pd}(\mathrm{XPhos}) \mathrm{Cl}$. ${ }^{\text {Crotyl }} \mathrm{Pd}(\mathrm{XPhos}) \mathrm{Cl}$ was slightly more active than ${ }^{\text {Cinnamyl }} \mathrm{Pd}(\mathrm{XPhos}) \mathrm{Cl}$, while ${ }^{\text {Allyl }} \mathrm{Pd}(\mathrm{XPhos}) \mathrm{Cl}$ only gives a yield of around $10 \%$. This trend in precatalyst performance is likely related to the relative rates of activation, which is proposed to occur via a solvent assisted pathway for the allyl-type systems under these reaction conditions.

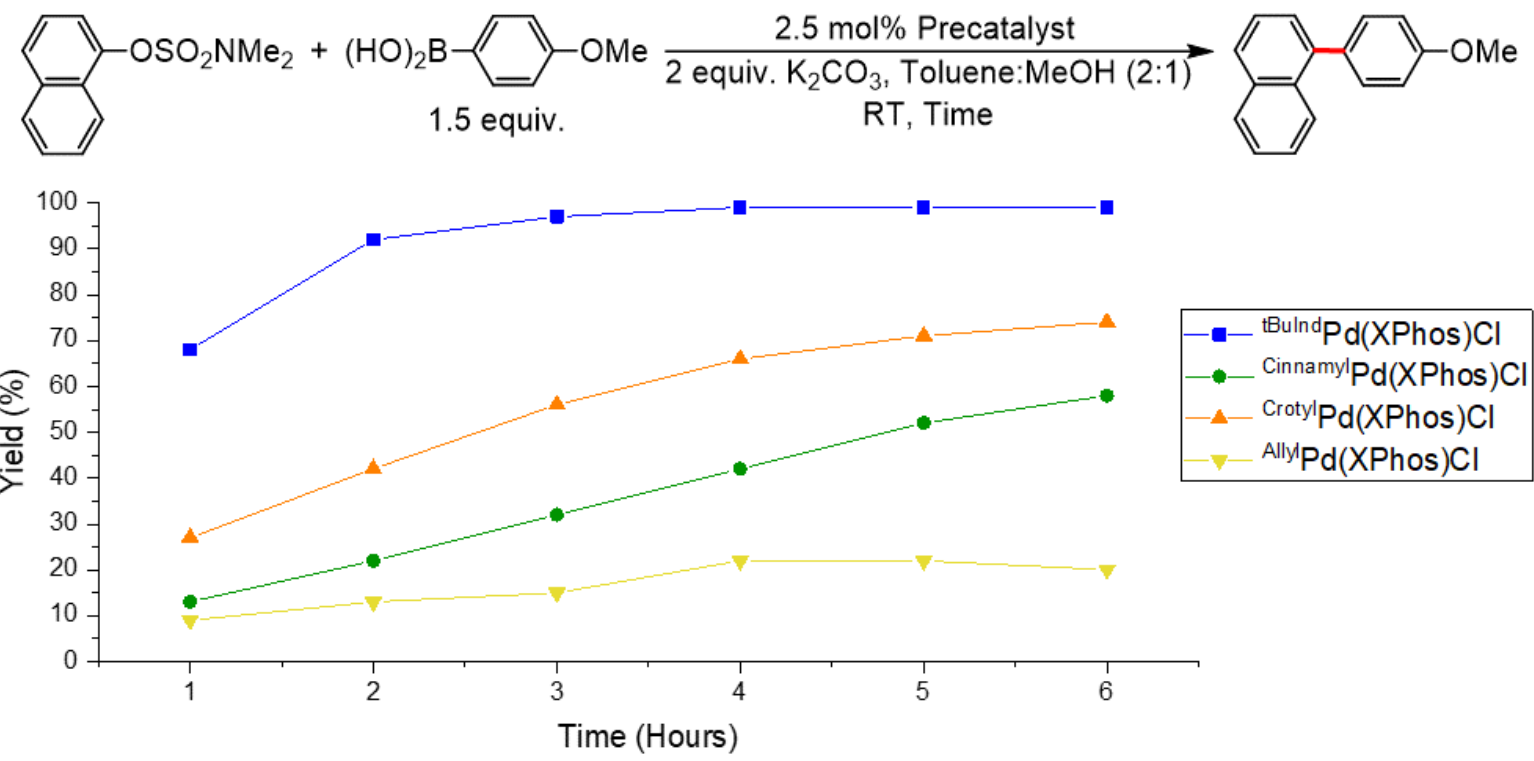

Figure 13: Yield versus time for the Suzuki-Miyaura coupling of 1-naphthyl sulfamate and 4methoxyphenyl boronic acid with different precatalysts. Reaction conditions: [1-naphthyl sulfamate] = $0.1 \mathrm{M}$, [Boronic Acid] $=0.15 \mathrm{M},[$ Base] $=0.2 \mathrm{M}$, [Precatalyst] $=0.0025 \mathrm{M}, 0.67 \mathrm{~mL}$ Toluene, and 0.33 $\mathrm{mL} \mathrm{MeOH}$. Product yield was determined through comparison of product signal with an internal naphthalene standard on a gas chromatogram with an FID detector. 
The vast majority of cross-coupling reactions involve the formation of $\mathrm{Csp}^{2}-\mathrm{Csp}^{2}$ bonds, but there is also significant interest in the formation of $\mathrm{Csp}^{2}-\mathrm{Csp}^{3}$ bonds, which are ubiquitous in pharmaceuticals, using cross-coupling. ${ }^{[23]}$ For example, palladium complexes supported by $\mathrm{P}^{\mathrm{t}} \mathrm{Bu}_{3}$ are known to be active for cross-coupling reactions between aryl halides and alkyl trifluoroborates to generate $\mathrm{Csp}^{2}-\mathrm{Csp}^{3}$ bonds. ${ }^{[24]}$ Here, we examined the coupling of 3-chloroanisole and potassium sec-butyltrifluoroborate with our library of precatalysts (Figure 14). The most active system was ${ }^{\text {tBuInd }} \mathrm{Pd}\left(\mathrm{P}^{t} \mathrm{Bu}_{3}\right) \mathrm{Cl}$. ${ }^{\text {Crotyl }} \mathrm{Pd}\left(\mathrm{P}^{t} \mathrm{Bu}_{3}\right) \mathrm{Cl}$ also displayed high activity, but there was a notable decrease in yield when either ${ }^{\text {Cinnamyll }} \mathrm{Pd}\left(\mathrm{P}^{t} \mathrm{Bu}_{3}\right) \mathrm{Cl}$ or ${ }^{\text {Allyl }} \mathrm{Pd}\left(\mathrm{P}^{t} \mathrm{Bu}_{3}\right) \mathrm{Cl}$ were used as precatalysts. Explaining the relative performance of the precatalysts in this case is complicated as with the relatively less bulky $\mathrm{P}^{\mathrm{t}} \mathrm{Bu}_{3}$ ligand palladium(I) dimer formation likely occurs. However, at this temperature palladium(I) dimer formation is probably reversible for some systems and as a result the observed trends likely depend on the rate of activation from palladium(II) to palladium(0) and the kinetics and thermodynamics associated with palladium(I) dimer dissociation, which generates the active species. ${ }^{[9,17]}$

Summary: Our experiments indicate that because sterically bulky phosphine ligands, such as XPhos, which do not allow for palladium(I) dimer formation, are commonly used to facilitate
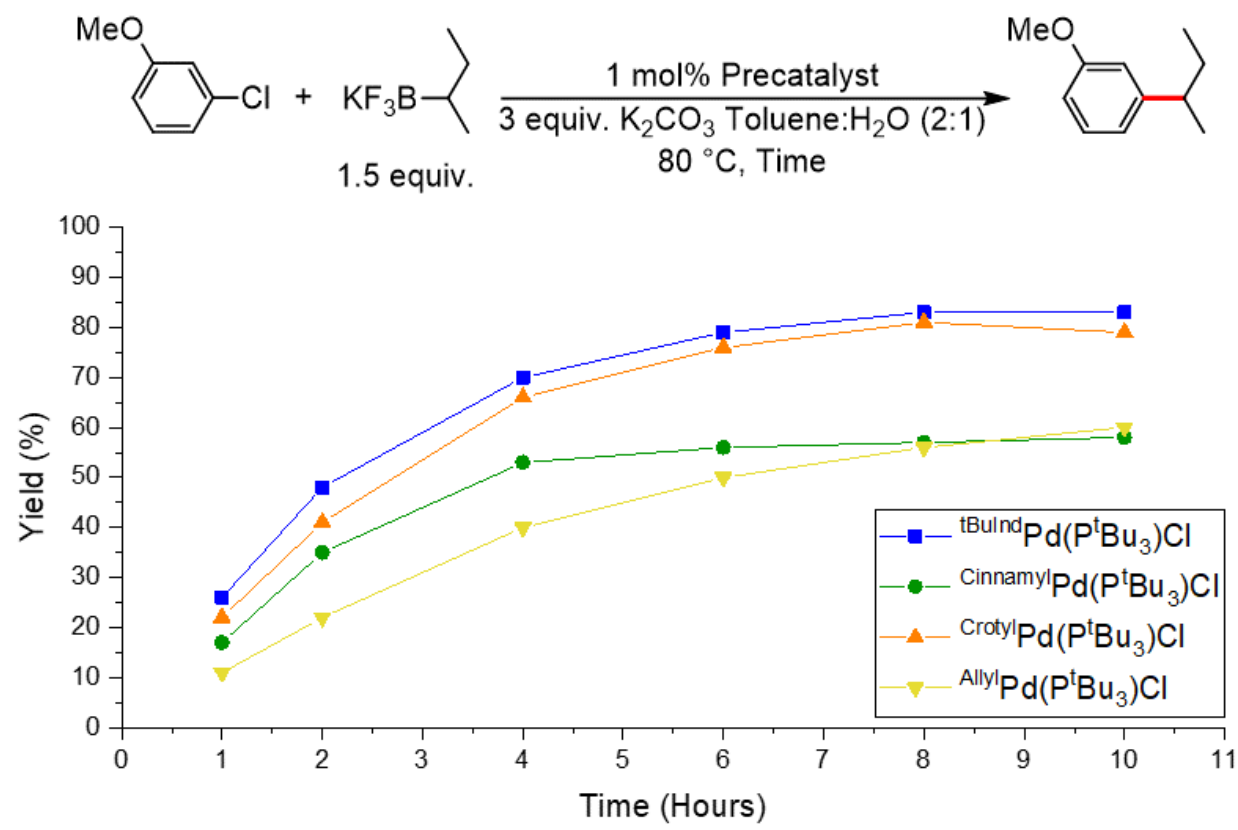

Figure 14: Yield versus time for the Suzuki-Miyaura coupling of 3-chloroanisole and potassium secbutyltrifluoroborate with different precatalysts. Reaction conditions: $[\mathrm{ArCl}]=0.33 \mathrm{M}$, [potassium secbutyltrifluoroborate $]=0.5 \mathrm{M},[$ Base $]=1 \mathrm{M}$, [Precatalyst $]=0.0033 \mathrm{M}, 0.67 \mathrm{~mL}$ Toluene, and $0.33 \mathrm{~mL}$ $\mathrm{H}_{2} \mathrm{O}$. Product yield was determined through comparison of product signal with an internal naphthalene standard on a gas chromatogram with an FID detector. 


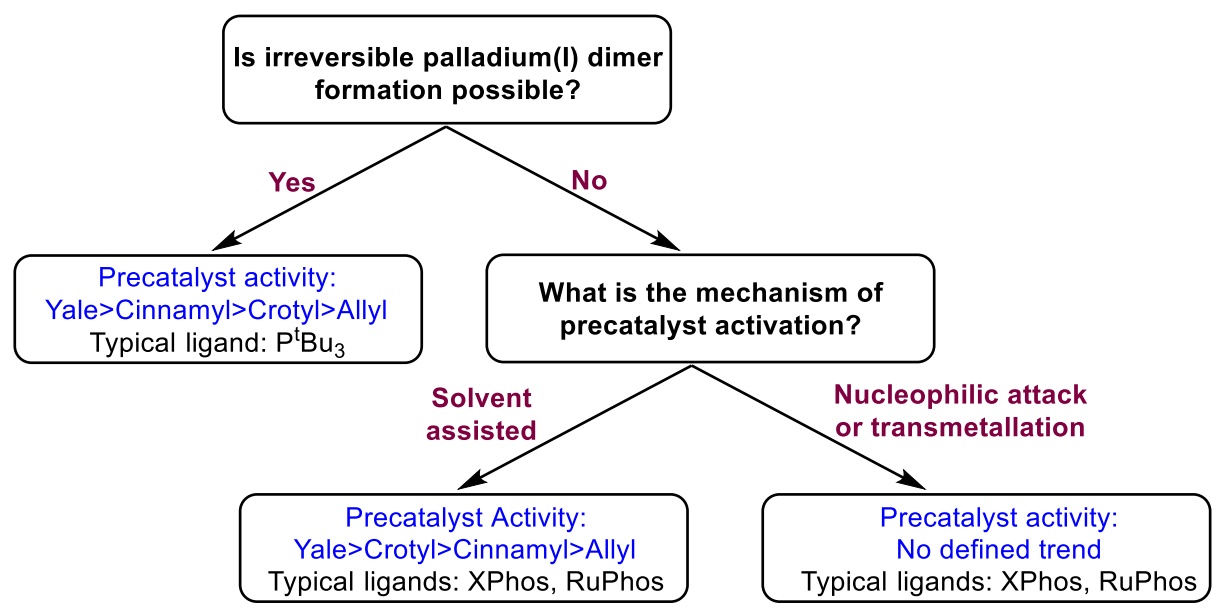

Figure 15: Decision tree for selecting phosphine ligated precatalysts.

cross-coupling reactions, the rate of activation from palladium(II) to palladium(0) is often the crucial factor in determining the relative precatalyst performance of allyl-based systems. This stands in contrast to NHC systems, where ligands like IPr, which do allow for palladium(I) dimer formation, are the most commonly used. When activation is the dominant factor, ${ }^{\mathrm{Crotyl}} \mathrm{Pd}\left(\mathrm{PR}_{3}\right) \mathrm{Cl}$ typically outperforms ${ }^{\text {Cinnamyl }} \mathrm{Pd}\left(\mathrm{PR}_{3}\right) \mathrm{Cl}$ regardless of the exact mechanism. Further, ${ }^{\text {tBuInd }} \mathrm{Pd}\left(\mathrm{PR}_{3}\right) \mathrm{Cl}$, which activates the fastest under the solvent assisted pathway, is normally the most active catalyst (Figure 15). However, our results indicate that the relative rates of precatalyst activation are dependent on the chosen substrates and conditions, and in cases where activation is the dominant factor and alternative mechanistic pathways are possible, such as coordination based transmetallation, a number of precatalysts should be evaluated.

\section{Coupling Reactions with Precatalysts Generated In Situ}

When researchers are assessing if new substrates can undergo cross-coupling reactions, the identity of the optimal ancillary ligand is often unclear. Given that the synthesis and isolation of a large number of welldefined precatalysts with different ligands is timeintensive, it is valuable to have methods to rapidly
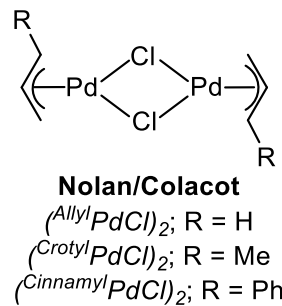
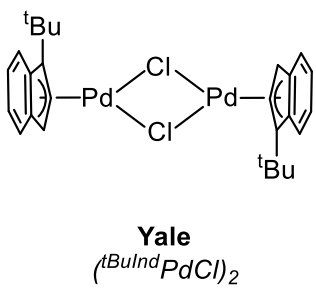

Figure 16: Unligated dimeric palladium(II) precursors used for in-situ precatalyst generation. screen a variety of ligands using in situ generated systems. The allyl, ${ }^{[6 \mathrm{~b}]}$ crotyl ${ }^{[6 \mathrm{~d}]}{ }^{\mathrm{cinnamyl}},{ }^{[6 \mathrm{~d}]}$, and Yale systems,${ }^{[7]}$ have unligated dimeric precursors (Figure 16), which can be converted into ligated precatalysts through reactions with free ligand in situ. In this section, we compare the activity of precatalysts generated in situ from these dimeric precursors with both NHC and phosphine ligands. Additionally, researchers often 
generate in situ systems for cross-coupling through the reaction of commercially available palladium sources such as tris(dibenzylideneacetone)dipalladium(0) $\left(\operatorname{Pd}_{2} \mathrm{dba}_{3}\right)$, bis(acetonitrile)palladium dichloride $\left(\mathrm{Pd}\left(\mathrm{CH}_{3} \mathrm{CN}\right)_{2} \mathrm{Cl}_{2}\right)$, and palladium acetate $\left(\mathrm{Pd}_{3}(\mathrm{OAc})_{6}\right)$ with free ligand. These systems are also included in our comparison. Finally, it was recently reported that commercially available palladium acetate often contains a nitrate impurity $\left(\mathrm{Pd}_{3}(\mathrm{OAc})_{5}\left(\mathrm{NO}_{2}\right) .{ }^{[25]}\right.$ Here, we compare the performance of pure palladium acetate with samples containing a nitrate impurity. The goal of this section is to assess if the trends elucidated for ligated versions of the precatalysts also apply to in situ generated systems and evaluate how the different precatalysts compare to simple commercially available palladium sources.

Simple aryl substrates: The first reaction we used for our comparison was the Suzuki-Miyaura coupling of 4-chlorotoluene with phenyl boronic acid using IPr as the ancillary ligand. In these reactions, the precatalysts were mixed with IPr for approximately 10 minutes before the substrates and base were added. Under the optimized conditions for allyl-type precatalysts, we found that differentiation between the Yale system, palladium acetate, and $\mathrm{Pd}\left(\mathrm{CH}_{3} \mathrm{CN}\right)_{2} \mathrm{Cl}_{2}$ was challenging due to their rapid generation of product (see SI). We, therefore, lowered the catalyst loading to

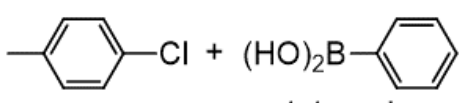

$\frac{0.25 \mathrm{~mol} \% \mathrm{Pd}, 0.25 \mathrm{~mol} \% \mathrm{IPr}}{1.1 \text { equiv. } \mathrm{KO}{ }^{\mathrm{t}} \mathrm{Bu}, \mathrm{MeOH}: \mathrm{THF}(19: 1), \mathrm{RT}, \text { Time }}$

1.1 equiv.

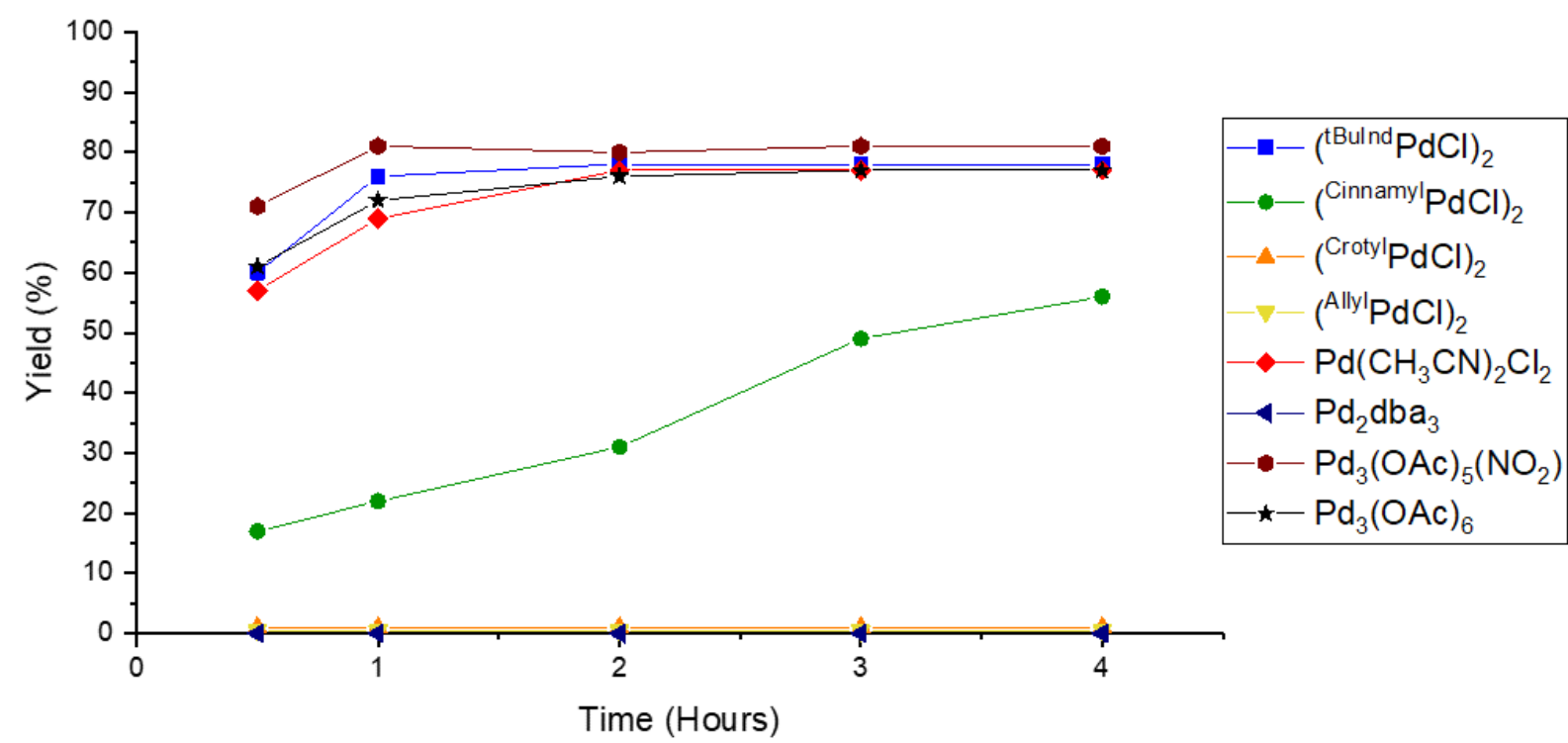

Figure 17: Yield versus time for the Suzuki-Miyaura coupling of 4-chlorotoluene and phenyl boronic acid using in-situ generated palladium XPhos precatalysts. Reaction conditions: $[\mathrm{ArCl}]=0.5 \mathrm{M}$, $[$ Boronic Acid $]=0.55 \mathrm{M},[$ Base $]=0.55 \mathrm{M},[\mathrm{Pd}]=0.00125 \mathrm{M},[\mathrm{IPr}]=0.00125 \mathrm{M}, 0.95 \mathrm{~mL} \mathrm{MeOH}$, and $0.05 \mathrm{~mL}$ THF. Product yield was determined through comparison of product signal with an internal naphthalene standard on a gas chromatogram with an FID detector. 
$0.25 \mathrm{~mol} \%$ (Figure 17) and observed that the dimeric version of the Yale precatalyst gives better performance than the cinnamyl, crotyl, or allyl systems. In fact, the allyl and crotyl systems give almost no activity, mirroring trends observed for the well-defined precatalysts (Figure 4). In general, for all the reactions evaluated in this section, the activity of well-defined precatalysts is always either comparable or higher than in situ generated systems, although there are some exceptions (see SI). This suggests that precatalyst performance is not related to the ligation event but connected to palladium(I) dimer formation and the rates of activation as observed using welldefined precatalysts. Surprisingly, precatalysts generated from both pure and impure palladium acetate and $\mathrm{Pd}\left(\mathrm{CH}_{3} \mathrm{CN}\right)_{2} \mathrm{Cl}_{2}$ resulted in high yields and give comparable activity to the dimeric version of the Yale precatalyst, demonstrating that for ligand screening purposes a system based on a precatalyst is not necessarily required. No activity, however, was observed when $\mathrm{Pd}_{2} \mathrm{dba}_{3}$ was used as the palladium source.

We subsequently evaluated the ability of the different palladium precursors to couple 4chlorotoluene and phenyl boronic acid when treated with XPhos in situ (Figure 18). As for the IPr supported systems, the trends in precatalyst performance for the in situ generated XPhos ligated

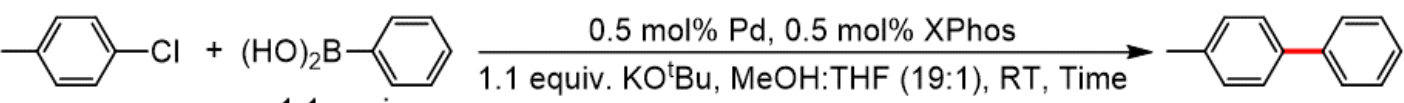

1.1 equiv.

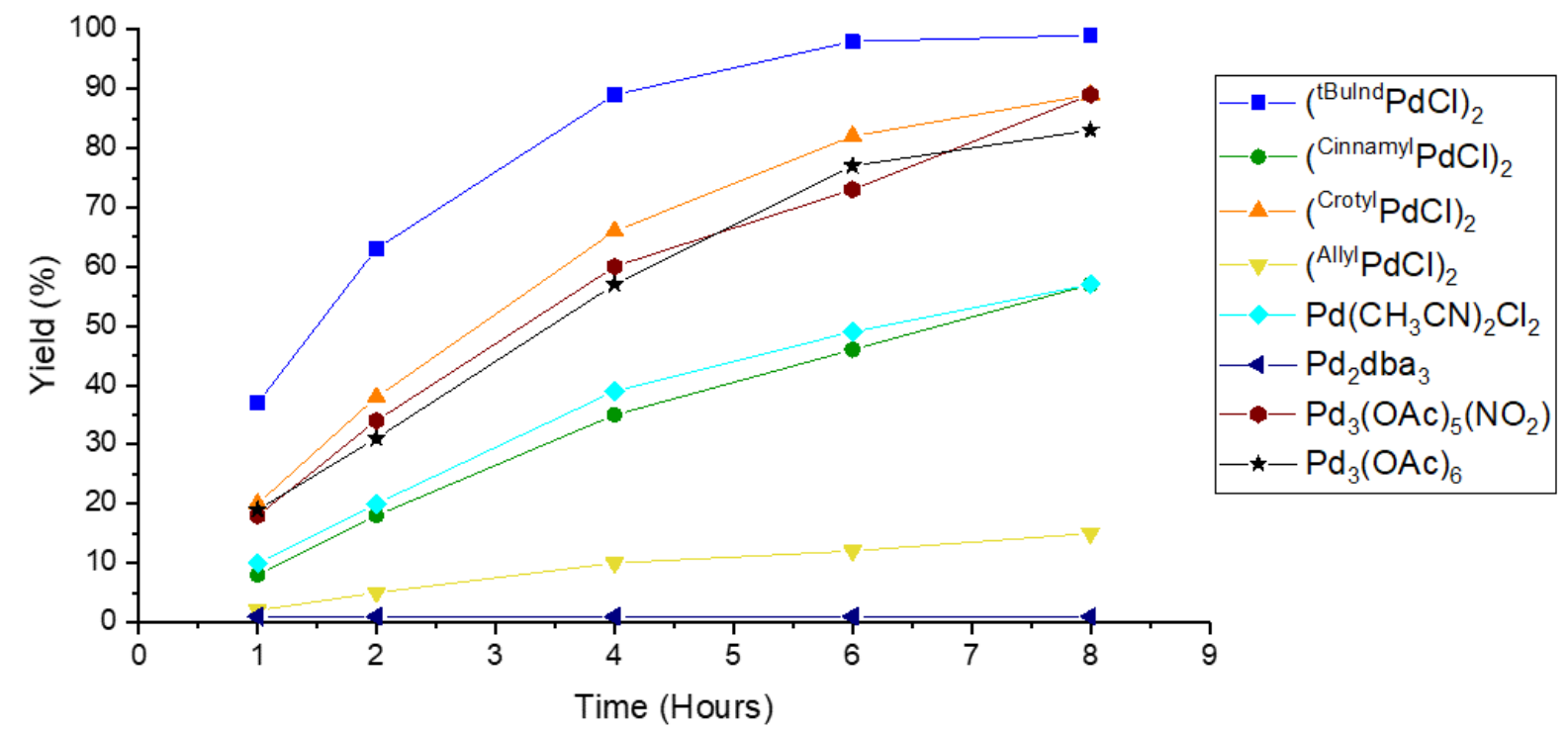

Figure 18: Yield versus time for the Suzuki-Miyaura coupling of 4-chlorotoluene and phenyl boronic acid using in-situ generated palladium XPhos precatalysts. Reaction conditions: $[\mathrm{ArCl}]=0.5 \mathrm{M}$, $[$ Boronic Acid $]=0.55 \mathrm{M},[$ Base $]=0.55 \mathrm{M},[\mathrm{Pd}]=0.0025 \mathrm{M},[\mathrm{XPhos}]=0.0025 \mathrm{M}, 0.95 \mathrm{~mL} \mathrm{MeOH}$, and $0.05 \mathrm{~mL}$ THF. Product yield was determined through comparison of product signal with an internal naphthalene standard on a gas chromatogram with an FID detector. 
systems are the same as those for well-defined systems (Figure 9). The Yale system gives higher activity than the crotyl system, which is more active than precatalysts formed from the cinnamyl or allyl dimers. Both the pure and impure palladium acetate sources give similar activity, which is approximately the same as that observed from the crotyl system. $\mathrm{Pd}\left(\mathrm{CH}_{3} \mathrm{CN}\right)_{2} \mathrm{Cl}_{2}$ gives comparable activity to the cinnamyl system, and $\mathrm{Pd}_{2} \mathrm{dba}_{3}$ does not result in the formation of active catalyst.

One of the problems associated with using in situ generated systems is that it is possible to have a ligand to palladium ratio that is not 1:1. This will occur if there is an error weighing out either the ligand or palladium source or if the ligation event does not proceed quantitatively. To evaluate the effect of excess palladium or ligand on catalytic performance with different palladium sources, we performed a series of XPhos supported couplings of 4-chlorotoluene and phenyl boronic acid with ligand to metal ratios of $0.8,1.0$, or 1.2 equivalents, respectively (Figure 19). For most systems, there were differences in catalytic performance when the ligand to metal ratio was changed. There was, however, significant variation in the magnitude and direction of these differences. For example, when the ratio of ligand to metal was increased from 0.8 to 1.2 equivalents using $\mathrm{Pd}\left(\mathrm{CH}_{3} \mathrm{CN}\right)_{2} \mathrm{Cl}_{2}$ as the palladium source, the yield decreased by a factor of sixteen from $64 \%$ to 4\%. In contrast, when $\mathrm{Pd}_{3}(\mathrm{OAc})_{6}$ is used as the palladium source, changing the ligand to metal
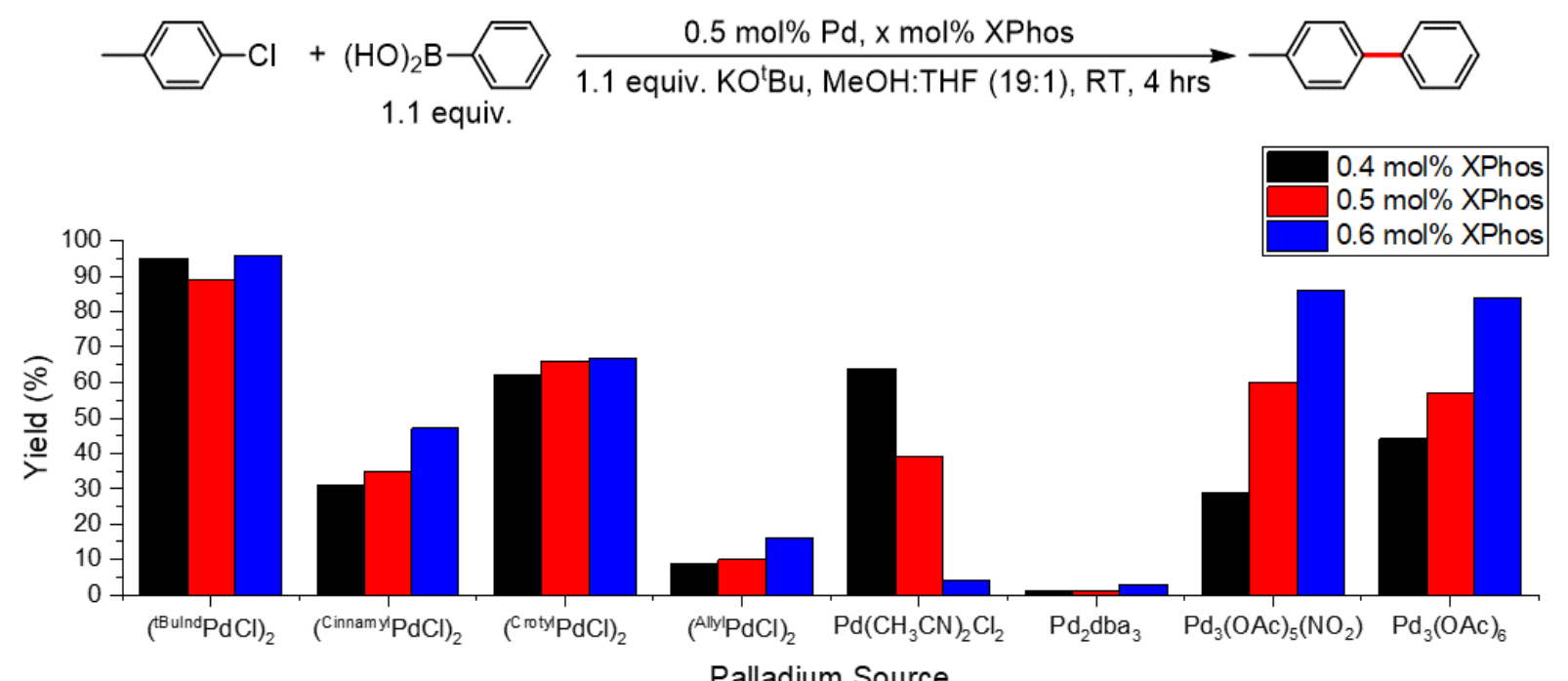

Figure 19: Comparative yields for the Suzuki-Miyaura coupling of 4-chlorotoluene and phenyl boronic acid using in-situ generated palladium XPhos precatalysts. Reaction conditions: $[\mathrm{ArCl}]=0.5 \mathrm{M}$, $[$ Boronic Acid $]=0.55 \mathrm{M}$, [Base $]=0.55 \mathrm{M},[\mathrm{Pd}]=0.0025 \mathrm{M},[$ XPhos $]=0.002 \mathrm{M}$ for 0.8 equiv. or $0.0025 \mathrm{M}$ for 1 equiv. or $0.003 \mathrm{M}$ for 1.2 equiv., $0.95 \mathrm{~mL} \mathrm{MeOH}$, and $0.05 \mathrm{~mL}$ THF. Product yield was determined through comparison of product signal with an internal naphthalene standard on a gas chromatogram with an FID detector. 
ratio from 0.8 to 1.2 equivalents nearly doubled the yield from $44 \%$ to $84 \%$. In this case, we suggest that excess phosphine aids the reaction because some phosphine is consumed in the reduction of palladium(II) acetate to the active palladium(0) catalyst, as has been previously proposed in the literature. ${ }^{[26]}$ In general, smaller differences were observed when the ligand to metal ratio was varied using the allyl based systems, which is perhaps another reason to use these more welldefined systems. Further, the trends in precatalyst performance were similar regardless of the number of equivalents of ligand. These results highlight that for some cross-coupling reactions, careful optimization of the number of equivalents of ligand may also be beneficial.

Heteroaryl substrates: We next explored the relative activity of in situ generated systems in two more complex Suzuki-Miyaura reactions, namely the couplings of 2-chloro-4,6dimethoxypyrimidine and benzo[b]furan-2-boronic acid and 2-chlorothiophene and 3-furan boronic acid in the presence of XPhos (Figure 20). Under the optimized conditions for allyl-type precatalysts, the same trends in catalyst performance were observed for the in situ generated
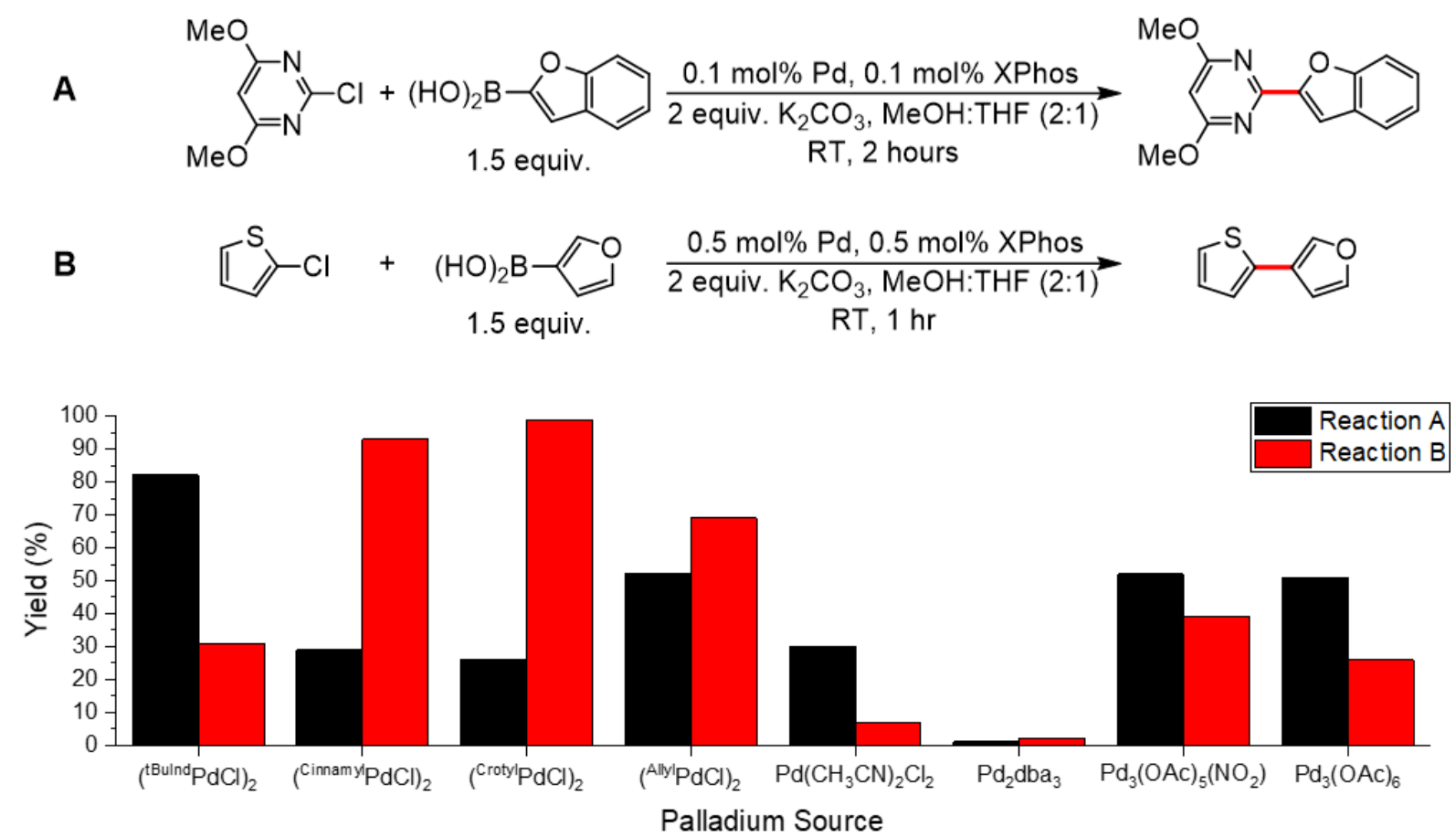

Figure 20: Comparative yields for the Suzuki-Miyaura coupling of heteroaryl boronic substrates using in situ generated XPhos precatalysts. Reaction A: The coupling of 2-chloro-4,6-dimethoxypyrimidine and benzo[b]furan-2-boronic acid. Reaction B: The coupling of 2-chlorothiophene and 3-furan boronic acid. Conditions for reactions $\mathrm{A}$ and $\mathrm{B}:[\mathrm{ArCl}]=0.3 \mathrm{M}$, [Boronic Acid] $=0.45 \mathrm{M},[$ Base $]=0.6 \mathrm{M},[\mathrm{Pd}]$ $=0.003 \mathrm{M}$, [XPhos $]=0.003 \mathrm{M}, 0.33 \mathrm{~mL}$ THF, and $0.67 \mathrm{~mL} \mathrm{MeOH}$. Product yield was determined through comparison of product signal with an internal naphthalene standard on a gas chromatogram with an FID detector. 
systems as for the well-defined precatalysts (Figures $10 \& 11$ ). Specifically, the Yale systems is the most active for coupling 2-chloro-4,6-dimethoxypyrimidine and benzo[b]furan-2-boronic acid, but the crotyl and cinnamyl systems are the most active for coupling 2-chlorothiophene and 3furan boronic acid. Of the common palladium sources, palladium acetate again displays the highest activity, while $\mathrm{Pd}_{2} \mathrm{dba}_{3}$ gives almost no activity.

Non-traditional electrophiles: To conclude this section, we evaluated the activity of our different palladium sources in the in situ $\mathrm{Csp}^{2}-\mathrm{Csp}^{3}$ Suzuki-Miyaura coupling of 3-chloroanisole and potassium sec-butyltrifluoroborate (Figure 21). Under the chosen conditions, the crotyl system displays higher activity than the Yale, cinnamyl, and allyl systems. This trend is slightly different to that observed using well-defined precatalysts (Figure 14), as the Yale system is relatively less active. This implies that the coordination of $\mathrm{P}^{t} \mathrm{Bu}_{3}$ occurs less readily for the Yale system compared to other systems, which may be related to its steric bulk. Additionally, to our surprise, all of the common palladium sources, $\mathrm{Pd}\left(\mathrm{CH}_{3} \mathrm{CN}\right)_{2} \mathrm{Cl}_{2}, \mathrm{Pd}_{2} \mathrm{dba}_{3}$, and palladium acetate, give low yields of product. This stands in contrast to other reactions performed in this section, which demonstrate that palladium acetate can give high activity. It suggests that care must be taken when screening different precursors as there is no apparent reason for palladium acetate to give a low yield in this case.
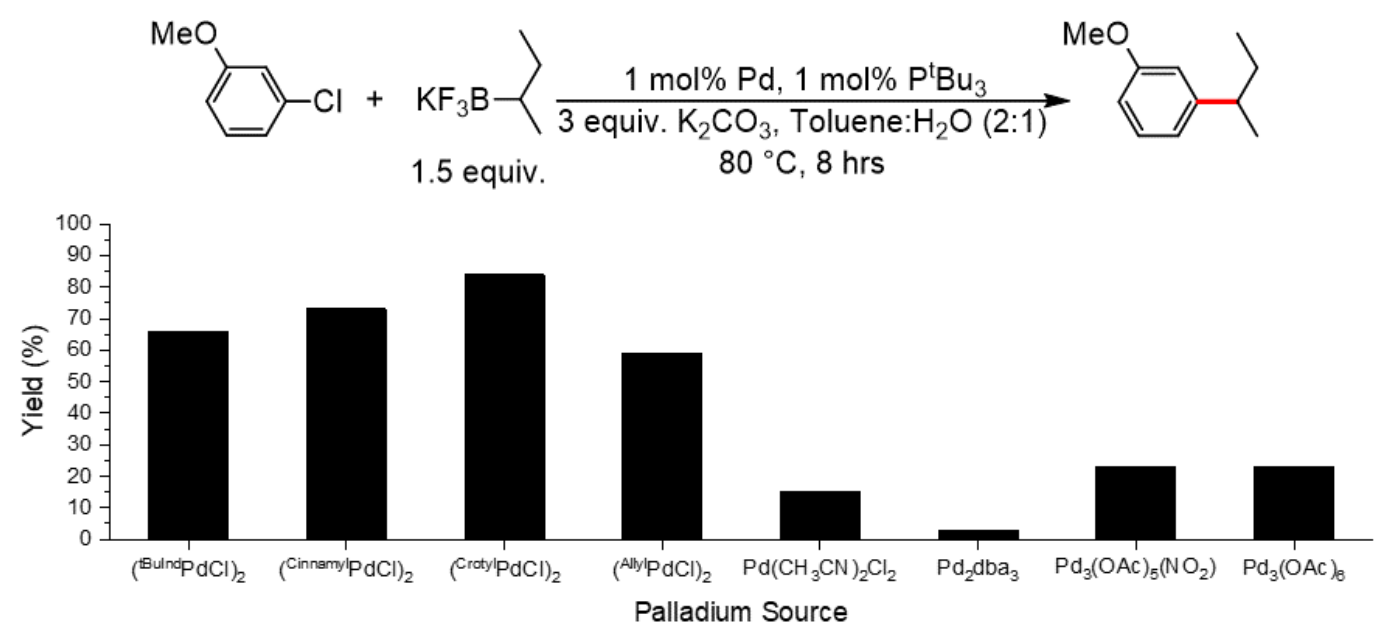

Figure 21: Comparative yields for the Suzuki-Miyaura coupling of 3-chloroanisole and potassium secbutyltrifluoroborate with different precatalysts. Reaction conditions: $[\mathrm{ArCl}]=0.33 \mathrm{M}$, [potassium secbutyltrifluoroborate $]=0.5 \mathrm{M},[$ Base $]=1 \mathrm{M},[\mathrm{Pd}]=0.0033 \mathrm{M},\left[\mathrm{P}^{\mathrm{t}} \mathrm{Bu}_{3}\right]=0.0033 \mathrm{M}, 0.67 \mathrm{~mL}$ Toluene, and $0.33 \mathrm{~mL} \mathrm{H}_{2} \mathrm{O}$. Product yield was determined through comparison of product signal with an internal naphthalene standard on a gas chromatogram with an FID detector. 
Summary: The results in this section highlight that the trends in catalyst performance for welldefined systems are typically the same as those observed using in situ generated systems. Therefore, the conclusions we reached about which precatalysts are optimal for different reactions using well-defined systems are the same for in situ generated experiments. This suggests that at least for the ligands studied in this work, the efficiency of ligation of the allyl precatalysts is approximately comparable. Interestingly, palladium acetate (both pure and impure) gives excellent activity for in situ reactions, and in some cases, it may be suitable to perform ligand screening using it as the palladium source. In this case, care needs to be taken about the exact number of equivalents of ligand that are added. In contrast, although $\mathrm{Pd}_{2} \mathrm{dba}_{3}$ is commonly used in the literature, our results show that for the reactions described in this paper, it should be avoided as a palladium source due to its low activity. Finally, our data indicates that once the optimal ligand and palladium source has been found, it is likely better to use a well-defined system than an in situ generated system.

\section{Conclusions}

In this work, we have compared the activity of a number of commercially available allyl-type for Suzuki-Miyaura reactions. In general, precatalysts based on an unsubstituted allyl ligand give significantly lower activity than other systems, and should not be widely utilized. When ligated with NHC ligands, precatalysts with a cinnamyl ligand typically give higher activity than precatalysts with a crotyl ligand, but this order reverses for phosphine supported species. In most of the reactions performed in this work, the Yale precatalyst gives higher activity than both the cinnamyl and crotyl systems with both NHC and phosphine ligands, but this is dependent on two factors: (i) whether the irreversible formation of palladium(I) dimer occurs; and (ii) the pathway for activation from palladium(II) to palladium(0). These are related to the ancillary ligand, substrates, and reaction conditions, and we have developed decision trees to help researchers choose a precatalyst. We note that the generality of our results remains to be determined, and it is not clear if our conclusions will be relevant to other cross-coupling reactions such as BuchwaldHartwig, Negishi, Stille, or Kumada reactions. Additionally, the allyl-type precatalysts are also

effective for performing initial ligand screening reactions, and our advice is to use either the Yale precatalyst or palladium acetate to perform an initial ligand screen before evaluating a range of well-defined precatalysts once a ligand has been identified. Overall, our results demonstrate the 
advantages of using precatalysts compared to unligated commercial palladium sources and provide guidance about which allyl-type precatalysts to use for different Suzuki-Miyaura reactions.

\section{Acknowledgements}

NH acknowledges support from the NIHGMS under Award Number R01GM120162. MRE acknowledges support from a Wiberg Graduate Research Fellowship. We are grateful to Amira Dardir and Vivek Suri for assistance with synthesis and fruitful discussion and Dr. Damian Hruszkewycz and Dr. Patrick Melvin for comments on the manuscript.

\section{Additional information}

Additional information about selected experiments, NMR spectra, and other details are available via the Internet.

\section{Competing Financial Interests}

This work was primarily funded by Umicore, who own the rights to all of the allyl-based precatalysts studied in this work. Additionally, $\mathrm{NH}$ is an inventor on patents relating to the Yale precatalyst.

\section{References}

[1] (a) K. C. Nicolaou, P. G. Bulger, D. Sarlah, Angew. Chem. Int. Ed. 2005, 44, 4442; (b) J.-P. Corbet, G. Mignani, Chem. Rev. 2006, 106, 2651; (c) S. L. Buchwald, Acc. Chem. Res. 2008, 41, 1439; (d) J. Magano, J. R. Dunetz, Chem. Rev. 2011, 111, 2177; (e) C. C. C. Johansson Seechurn, M. O. Kitching, T. J. Colacot, V. Snieckus, Angew. Chem. Int. Ed. 2012, 51, 5062; (f) P. G. Gildner, T. J. Colacot, Organometallics 2015, 34, 5497; (g) P. Ruiz-Castillo, S. L. Buchwald, Chem. Rev. 2016, 116, 12564; (h) L.-C. Campeau, N. Hazari, Organometallics 2019, $38,3$.

[2] (a) Q. Shelby, N. Kataoka, G. Mann, J. Hartwig, J. Am. Chem. Soc. 2000, 122, 10718; (b) N. Kataoka, Q. Shelby, J. P. Stambuli, J. F. Hartwig, J. Org. Chem. 2002, 67, 5553; (c) G. C. Fu, Acc. Chem. Res. 2008, 41, 1555; (d) N. Marion, S. P. Nolan, Acc. Chem. Res. 2008, 41, 1440; (e) S. Würtz, F. Glorius, Acc. Chem. Res. 2008, 41, 1523; (f) R. Martin, S. L. Buchwald, Acc. Chem. Res. 2008, 41, 1461; (g) D. S. Surry, S. L. Buchwald, Chem. Sci. 2011, 2, 27; (h) R. J. Lundgren, M. Stradiotto, Chem. Eur. J. 2012, 18, 9758; (i) L. Chen, P. Ren, B. P. Carrow, J. Am. Chem. Soc. 2016, 138, 6392; (j) R. D. J. Froese, C. Lombardi, M. Pompeo, R. P. Rucker, M. G. Organ, Acc. Chem. Res. 2017, 50, 2244.

[3] (a) H. Li, C. C. C. Johansson Seechurn, T. J. Colacot, ACS Catal. 2012, 2, 1147; (b) N. Hazari, P. R. Melvin, M. M. Beromi, Nat. Rev. Chem. 2017, 1, 0025; (c) K. H. Shaughnessy, Isr. J. Chem. 2020, 60, In Press.

[4] (a) M. R. Biscoe, B. P. Fors, S. L. Buchwald, J. Am. Chem. Soc. 2008, 130, 6686; (b) T. Kinzel, Y. Zhang, S. L. Buchwald, J. Am. Chem. Soc. 2010, 132, 14073; (c) N. C. Bruno, M. T. Tudge, S. L. Buchwald, Chem. Sci. 2013, 4, 916; (d) N. C. Bruno, N. Niljianskul, S. L. Buchwald, J. Org. Chem. 2014, 79, 4161; (e) A. Bruneau, M. Roche, M. Alami, S. Messaoudi, ACS Catal. 2015, 5, 1386.

[5] (a) C. J. O'Brien, E. A. B. Kantchev, C. Valente, N. Hadei, G. A. Chass, A. Lough, A. C. Hopkinson, M. G. Organ, Chem. Eur. J. 2006, 12, 4743; (b) M. G. Organ, G. A. Chass, D.-C. Fang, A. C. Hopkinson, C. Valente, Synthesis 2008, 2008, 2776; (c) J. Nasielski, N. Hadei, G. Achonduh, E. A. B. Kantchev, C. J. O'Brien, A. Lough, M. G. Organ, Chem. Eur. J. 2010, 16, 10844; (d) C. Valente, S. Çalimsiz, K. H. Hoi, D. Mallik, M. Sayah, M. G. Organ, Angew. Chem. Int. Ed. 2012, 51, 3314.

[6] (a) M. S. Viciu, R. F. Germaneau, S. P. Nolan, Org. Lett. 2002, 4, 4053; (b) M. S. Viciu, R. F. Germaneau, O. Navarro-Fernandez, E. D. Stevens, S. P. Nolan, Organometallics 2002, 21, 5470; (c) O. Navarro, H. Kaur, P. Mahjoor, S. P. Nolan, J. Org. Chem. 2004, 69, 3173; (d) N. Marion, O. Navarro, J. Mei, E. D. Stevens, N. M. Scott, S. P. Nolan, 
J. Am. Chem. Soc. 2006, 128, 4101; (e) A. J. DeAngelis, P. G. Gildner, R. Chow, T. J. Colacot, J. Org. Chem. 2015, 80, 6794.

[7] P. R. Melvin, A. Nova, D. Balcells, W. Dai, N. Hazari, D. P. Hruszkewycz, H. P. Shah, M. T. Tudge, ACS Catal. $\mathbf{2 0 1 5}, 5,3680$.

[8] L. L. Hill, J. L. Crowell, S. L. Tutwiler, N. L. Massie, C. C. Hines, S. T. Griffin, R. D. Rogers, K. H. Shaughnessy, G. A. Grasa, C. C. C. Johansson Seechurn, H. Li, T. J. Colacot, J. Chou, C. J. Woltermann, J. Org. Chem. 2010, 75, 6477.

[9] D. P. Hruszkewycz, D. Balcells, L. M. Guard, N. Hazari, M. Tilset, J. Am. Chem. Soc. 2014, 136, 7300.

[10] P. R. Melvin, D. Balcells, N. Hazari, A. Nova, ACS Catal. 2015, 5, 5596.

[11] DFT calculations suggest that the concerted process involving hydrogen transfer is lower in energy than an alternative pathway involving $\beta$-hydride elimination followed by reductive elimination. See reference 10 for more information.

[12] S. Borjian, M. C. Baird, Organometallics 2014, 33, 3936.

[13] D. Ortiz, M. Blug, X.-F. L. Goff, P. L. Floch, N. Mezailles, P. Maître, Organometallics 2012, 31, 5975.

[14] D. G. Brown, J. Boström, J. Med. Chem. 2016, 59, 4443.

[15] The Buchwald-Hartwig reaction is the next most common cross-coupling reaction performed in medicinal chemistry. In the Supporting Information the comparative performance of different precatalysts for a limited number of Buchwald-Hartwig reactions is described.

[16] (a) G. A. Grasa, M. S. Viciu, J. Huang, C. Zhang, M. L. Trudell, S. P. Nolan, Organometallics 2002, 21, 2866; (b) M. S. Viciu, O. Navarro, R. F. Germaneau, R. A. Kelly, W. Sommer, N. Marion, E. D. Stevens, L. Cavallo, S. P. Nolan, Organometallics 2004, 23, 1629; (c) R. Singh, M. S. Viciu, N. Kramareva, O. Navarro, S. P. Nolan, Org. Lett. 2005, 7, 1829; (d) O. Navarro, N. Marion, J. Mei, S. P. Nolan, Chem. Eur. J. 2006, 12, 5142; (e) E. A. B. Kantchev, C. J. O'Brien, M. G. Organ, Angew. Chem. Int. Ed. 2007, 46, 2768; (f) G. C. Fortman, S. P. Nolan, Chem. Soc. Rev. 2011, 40, 5151.

[17] C. C. C. Johansson Seechurn, S. L. Parisel, T. J. Colacot, J. Org. Chem. 2011, 76, 7918.

[18] (a) S. D. Roughley, A. M. Jordan, J. Med. Chem. 2011, 54, 3451; (b) P. A. Cox, A. G. Leach, A. D. Campbell, G. C. Lloyd-Jones, J. Am. Chem. Soc. 2016, 138, 9145; (c) P. A. Cox, M. Reid, A. G. Leach, A. D. Campbell, E. J. King, G. C. Lloyd-Jones, J. Am. Chem. Soc. 2017, 139, 13156.

[19] (a) A. Chartoire, M. Lesieur, L. Falivene, A. M. Z. Slawin, L. Cavallo, C. S. J. Cazin, S. P. Nolan, Chem. Eur. J. 2012, 18, 4517; (b) F. Izquierdo, S. Manzini, S. P. Nolan, Chem. Commun. 2014, 50, 14926; (c) G. Bastug, S. P. Nolan, Organometallics 2014, 33, 1253.

[20] (a) T. Ben Halima, W. Zhang, I. Yalaoui, X. Hong, Y.-F. Yang, K. N. Houk, S. G. Newman, J. Am. Chem. Soc. 2017, 139, 1311; (b) P. Lei, G. Meng, S. Shi, Y. Ling, J. An, R. Szostak, M. Szostak, Chem. Sci. 2017, 8, 6525; (c) A. H. Dardir, P. R. Melvin, R. M. Davis, N. Hazari, M. Mohadjer Beromi, J. Org. Chem. 2018, 83, 469.

[21] (a) T. Mesganaw, N. K. Garg, Org. Proc. Res. Dev. 2013, 17, 29; (b) B. M. Rosen, K. W. Quasdorf, D. A. Wilson, N. Zhang, A.-M. Resmerita, N. K. Garg, V. Percec, Chem. Rev. 2011, 111, 1346; (c) D.-G. Yu, B.-J. Li, Z.-J. Shi, Acc. Chem. Res. 2010, 43, 1486.

[22] P. R. Melvin, N. Hazari, M. M. Beromi, H. P. Shah, M. J. Williams, Org. Lett. 2016, 18, 5784.

[23] R. Jana, T. P. Pathak, M. S. Sigman, Chem. Rev. 2011, 111, 1417.

[24] L. Li, S. Zhao, A. Joshi-Pangu, M. Diane, M. R. Biscoe, J. Am. Chem. Soc. 2014, 136, 14027.

[25] W. A. Carole, J. Bradley, M. Sarwar, T. J. Colacot, Org. Lett. 2015, 17, 5472.

[26] C. Amatore, A. Jutand, A. Thuilliez, Organometallics 2001, 20, 3241. 


\section{TOC Graphic}

Comparison of Allyl Pd" Precatalysts for Suzuki-Miyaura Cross-Coupling

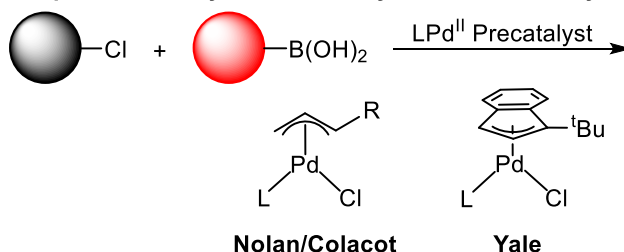

- Phosphine and NHC ligands tested 